SCIENCE \& TECHNOLOGY
Journal homepage: http://www.pertanika.upm.edu.my/

Review article

\title{
A Review on Synthesis and Characterization of Activated Carbon from Natural Fibers for Supercapacitor Application
}

\author{
Thilageshwaran Subramaniam ${ }^{1}$, Mohamed Ansari Mohamed Nainar ${ }^{1,2 *}$ and \\ Noor Afeefah Nordin ${ }^{2}$ \\ ${ }^{1}$ Mechanical Engineering Department, Universiti Tenaga National, 43000 UNITEN, Kajang, Malaysia \\ ${ }^{2}$ Institute of Power Engineering, Universiti Tenaga National, 43000 UNITEN, Kajang, Malaysia
}

\begin{abstract}
Supercapacitors have gained much attention in recent years due to their promising characteristics, such as high specific capacitance, high power density, long cycle life, and environment-friendly nature. Usage of natural sources for activated carbon synthesis is a major focus by many researchers worldwide for discovering a replacement of existing supercapacitors. This review summarizes the methods used to synthesize activated carbon (AC) from various natural fiber, their physical and electrochemical characteristics, and the improvement of supercapacitor electrode performance. Previous research studies indicate the practicability of activated carbon derived from various natural fibers with superior electrochemical properties. The effect of activating reagents and temperature on the electrochemical performance for supercapacitor applications are also highlighted in this paper. Since the nature of activated carbon from fibers and its synthesizing methods would result in different properties, the Cyclic Voltammetry (CV) study is also thoroughly discussed on the specific capacitance together with charge/discharge test to observe the capacitance retention after several cycles. Finally, a detailed approach

ARTICLE INFO

Article history:

Received: 29 April 2021

Accepted: 05 August 2021

Published: 10 January 2022 of converting biowaste materials to activated carbon for energy storage applications with environmental concerns is explored.
\end{abstract}

DOI: https://doi.org/10.47836/pjst.30.1.20

$\overline{\text { E-mail addresses: }}$

thilagesh.97@gmail.com (Thilageshwaran Subramaniam) ansari@uniten.edu.my (Mohamed Ansari Mohamed Nainar)

afeefahnordin1@gmail.com (Noor Afeefah Nordin)

* Corresponding author

Keywords: Activated carbon (AC), electric double-layer capacitor (EDLC), natural fibers, pseudocapacitor, supercapacitor electrode 


\section{INTRODUCTION}

Supercapacitors are devices used to store electrical energy undergoing frequent chargedischarge cycles at high currents in short time duration. It can be used in various applications, including electric vehicles, power grids, and wearable devices, due to its high specific capacitance (Zequine et al., 2017). In the 1950s, the first few ideas of storing electrical charges in an electric double layer were patented. There was much interest in the fact that charge could be stored with the interface between a solid and an electrolyte back then. Standard Oil Company developed the technology in Cleveland, and it was then licensed to Nippon Electric Company (NEC) in 1971. After that, NEC started to manufacture lowpowered devices for memory backup with the name "Supercapacitor." Then the technology was developed for military use by the Pinnacle Research Institute (PRJ) in 1982. The development of supercapacitors is carried out till today, where electrochemical double-layer capacitors (EDLCs) are commercially available from several sources (Namisnyk \& Zhu, 2003). In the current era, the development of supercapacitors offers a promising method to encounter the growing demands of conventional energy storage applications. With higher power density than batteries and larger energy density compared to conventional capacitors, supercapacitors have an important position to narrow the gap between batteries and conventional capacitors (Liu et al., 2019).

Supercapacitors (SCs) have gained interest in energy storage applications due to renewable energy sources. The burning of fossil fuels causes environmental concerns, and it is non-renewable energy that will eventually get used up. Therefore, renewable energy is being focused on countering the depletion of fossil fuels (Thulasi et al., 2019). Conversely, most renewable energy sources are unstable and continuous, such as wind and solar energy. Therefore, a promising energy storage system is crucial to use these energy sources optimally (Wu et al., 2015). The conventional technique for electrical energy storage uses batteries owing to their high energy density. However, batteries possess low power density, unlike supercapacitors with the superior power density and cycling stability but low energy density. One of the important properties of SCs is the rapid charging and discharging of electrical energy, which makes it a perfect tool for the instant storage of energy (Chowdhury \& Grebel, 2019). The advantages of using supercapacitors compared to batteries are its high power density, rapid charging, and discharging abilities, longer life cycles, and safer contrasted to batteries (Enock et al., 2017). Besides high power density and rapid charge-discharge properties, $\mathrm{SC}$ also has wide operating temperatures that make it more flexible to be used for various applications (Wei et al., 2019). There are three main supercapacitors categories: electric double-layer capacitors (EDLC), pseudocapacitors, and hybrid capacitors (Rawal et al., 2018). In the case of EDLC, the capacitance is produced as a result of a build-up of static charge at the electrode and electrolyte interface, whereby absorption and desorption occur by charged ions. 
Hereafter, large specific surface area (SSA) and high porosity are essential to obtain excellent capacitance for a supercapacitor (Lu et al., 2020). In the case of pseudocapacitance, it attains capacitance by surface-level rapid redox reactions of an electroactive material; meanwhile, the working principle for hybrid supercapacitors is by the combination of electric doublelayer capacitors and pseudocapacitors. The electrode materials used in pseudocapacitors are metal oxides and sulfides (Chime et al., 2020; Shinde \& Jun 2020). However, the supercapacitors encounter some issues, such as low conductivity of electricity and deprived charge-discharge cycles. Therefore,

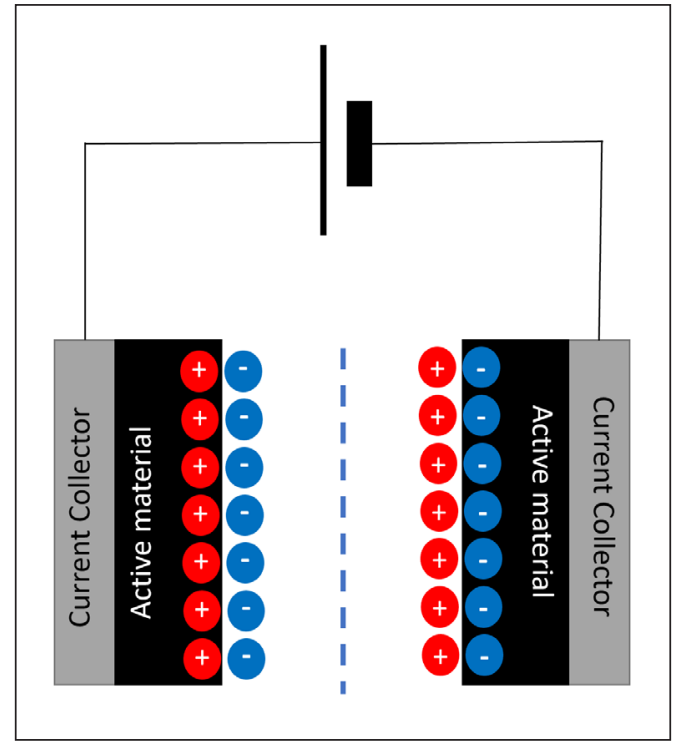

Figure 1. Cross-sectional view of EDLC various research projects are conducted to improve the electrochemical performance of the material used for supercapacitor electrodes. One of the ways to maximize the performance of EDLCs is by using carbon electrodes, as shown in Figure 1.

Carbon-based materials that are commonly used for the preparation of electrodes are activated carbon (AC), carbon nanotubes (CNT), aerogels, graphene as well as carbon fibers (S. Chen et al., 2020; Lyu et al., 2019; Tsang et al., 2020; Yar et al., 2020). AC is among the highly chosen active materials for supercapacitor electrodes, attributed to high thermal stability and electrical conductivity, corrosion resistance, high surface area after the carbonization process, and low cost (Luo et al., 2021). In addition, AC has a long history of usage and production for various purposes. For example, some of the activated carbons are used for the removal of heavy metals and chromium from solution, carbon dioxide capturing, hydrogen gas storage, air pollution control, and electrical energy applications (Ahmed et al., 2019). In general, the process of producing activated carbon from biomass materials is comparatively easy and cheaper contrasted to other carbon materials (Morali et al., 2018).

The process of producing activated carbon comprises carbonization and is followed by activation. Carbon activation is performed to progress the surface area of the carbon, which increases adsorption and desorption of electrolyte ions from the active surfaces of the activated carbon during the charging and discharging process. In addition, a high degree of randomness and defective graphite structure in the AC leads to the development of a broad range of its porosity. The pore size of AC ranges from visible cracks and crevices to molecular dimensions (Yu et al., 2019). Activating agents are used to increase the pore 
numbers in the carbon materials and to remove debris. As a result, the interaction between the active material and the electrolyte is enhanced as the active surface area increases (Musa et al., 2015; Tounsadi et al., 2016). Figure 2 shows the effect of the activating agent before and after the activation process. It can be observed that the fibers are cleaner without the presence of debris, and porosity increases after the activation.

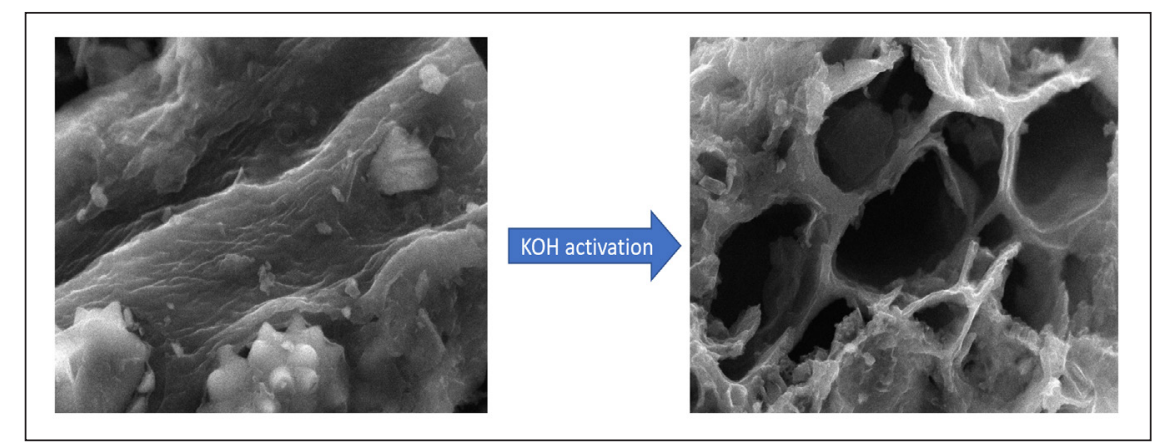

Figure 2. Scanning electron microscopic images of the activated carbon after $\mathrm{KOH}$ activation

Considering the recent advancements in technology for the development of supercapacitors, abundant potential renewable sources, and huge demand from various industrial sectors, this review serves to summarize the previous works related to the fabrication of supercapacitor electrode materials from natural fibers and elaborate on the findings obtained during the past five years. In addition, common types of supercapacitor electrodes are also briefly discussed and mainly focused on EDLCs with the usage of activated carbon as active material.

\section{SUPERCAPACITORS CLASSIFICATION}

Supercapacitors can be characterized depending on the energy storage system, primarily alluding to faradaic and non-faradaic electrodes. In non-faradaic electrodes, the electrochemical reaction does not occur; however, only charge adsorption/desorption arises at the interface when charging and discharging take place. On the other hand, faradaic capacitors undergo a fast reduction and oxidation process to store and release charge during charging and discharging of the supercapacitor (Arunachalam et al., 2020).

\section{Electric Double-Layer Capacitors (EDLC)}

EDLC is a non-faradaic capacitor based on an electrolyte and a double layer at the electrode interface. It functions with the build-up of electrostatic charges at the electrolyte/electrode interface, and the charge storage for a high capacitance supercapacitor is very much dependent on the escalation of surface area (Tan \& Lee, 2013). Overall, 1000-2000 m $\mathrm{g}^{-1}$ is the range for a high surface area of carbon electrodes. In comparison with traditional 
capacitors, the pore size distribution of EDLC has an increasing effect on the energy density (Gu \& Yushin, 2014; Xiong et al., 2014). Furthermore, since EDLCs use aqueous electrolytes, such as $\mathrm{H}_{2} \mathrm{SO}_{4}, \mathrm{KOH}$, or organic electrolytes, this could enhance the cycle stability during the charge-discharge processes (Bhat et al., 2021).

\section{Pseudocapacitor}

Pseudocapacitors are faradaic capacitors that store charges through the rapid transfer of charges between the electrolyte and the active material of the electrode (Devillers et al., 2014). The pseudocapacitors charge storage mechanism contrasts with EDLC, whereby the transfer of charge occurring is by voltage-dependent redox reaction, desorption, and adsorption or intercalation of ions. The redox reaction process in pseudocapacitors would result in superior energy density and capacitance. On the other hand, the Faradaic process occurs in dissimilar behaviors whereby the ions in the electrolyte are adsorbed to the metal surface in the initial stage. It was then followed by a reversible redox reaction (reduction and oxidation process) in the oxides/hydroxides of transition metal. The pseudocapacitor electrode surface area is crucial for these two reactions (Sayyed et al., 2019). The third stage involves bulk reversible doping and de-doping processes in the conducting polymers, which are less dependent on the surface area (Devillers et al., 2014).

The faradaic and non- faradaic processes are the primary dissimilarity between EDLCs and pseudocapacitance. Pseudocapacitors have rapid and reversible redox reactions between electrolyte and active material (Simon \& Gogotsi, 2008). Therefore, a pseudocapacitor's charge transfer process is similar to a battery during the charging and discharging process. Hence, the capacitance of a supercapacitor can be illustrated as shown in Equation 1. Capacitance $(C)$ is defined as the ratio of stored charge $(\Delta q)$ to change in potential $(\Delta V)$ (Raju \& Ozoemena, 2015).

$$
C=\frac{\Delta q}{\Delta V}
$$

\section{Hybrid Supercapacitors}

The merging of the Faradaic process and non-Faradaic process forms hybrid supercapacitors. The combination of high pseudocapacitance with capacitance from the electric double layer enables high power density and ensures long cycle life. The hybrid capacitors, which have combined EDLCs and pseudocapacitors, have greater electrochemical performance than EDLCs and pseudocapacitors (Afif et al., 2019). Improved devices can be obtained through the energy storage mechanism of a hybrid supercapacitor, which has a combo of Faradaic and Non-Faradaic processes (Bogeat, 2021). The common types of hybrid supercapacitors and their active materials are as shown in Figure 3 (Saini et al., 2021). 


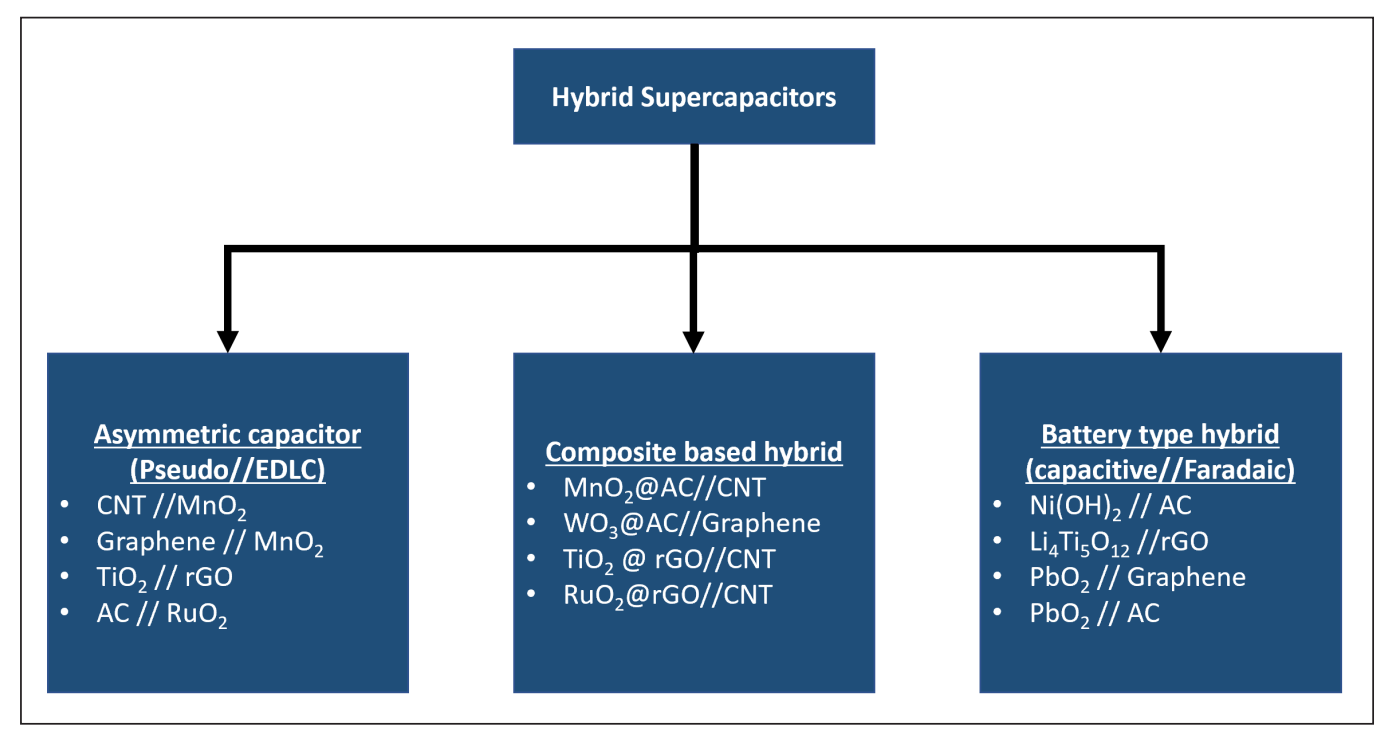

Figure 3. Types of hybrid supercapacitors

\section{RECOVERY OF CARBON FROM NATURAL FIBRES}

Commonly, the process of creating activated carbon is simpler and inexpensive compared to other carbon materials, specifically from biomass materials (Moral1 et al., 2018). Thermal treatment of biomass material demonstrates a change in porosity, surface area, and pore structures (Ioannidou \& Zabaniotou, 2007). Some research works have proven that AC from natural fibers has adsorption rates of 2 to 50 times faster than AC from coal. It is explained that the fibers with a small diameter (about $10 \mu \mathrm{m}$ ) show a larger external surface area (Rombaldo \& Lisboa, 2014). The two main steps involved in producing AC are carbonization and activation. Some of the natural fibers discussed in this review are shown in Figure 4.

Carbonization is the process of converting organic matters like natural fibers into carbon. There are two types of activations, which are chemical and physical activation. In physical activation, steam or $\mathrm{CO}_{2}$ is used to boost the porosity of the AC. Steam is extra effective in producing $\mathrm{AC}$ with a practically higher surface area than $\mathrm{CO}_{2}$ as the smaller molecular size of water molecules helps to enable diffusion within the carbon's porous structure (Im et al., 2019; Qin, 2019). Steam activation is testified to have a faster conversion degree than $\mathrm{CO}_{2}$ activation (Lei et al., 2018; Ma et al., 2020). On the other hand, chemical activation uses chemical agents, such as $\mathrm{KOH}$ (W. Chen et al., 2020; Zhu et al., 2019), $\mathrm{ZnCl}_{2}$ (Chen et al., 2018; Sun, 2019), $\mathrm{NaOH}$ (Hu et al., 2018; Zhang et al., 2019), and $\mathrm{H}_{3} \mathrm{PO}_{3}$ to synthesize activated carbon (Yakout \& Sharaf El-Deen, 2016). In addition, chemical activation occurs at lower activation temperature compared to physical activation (Nor et al., 2013). 

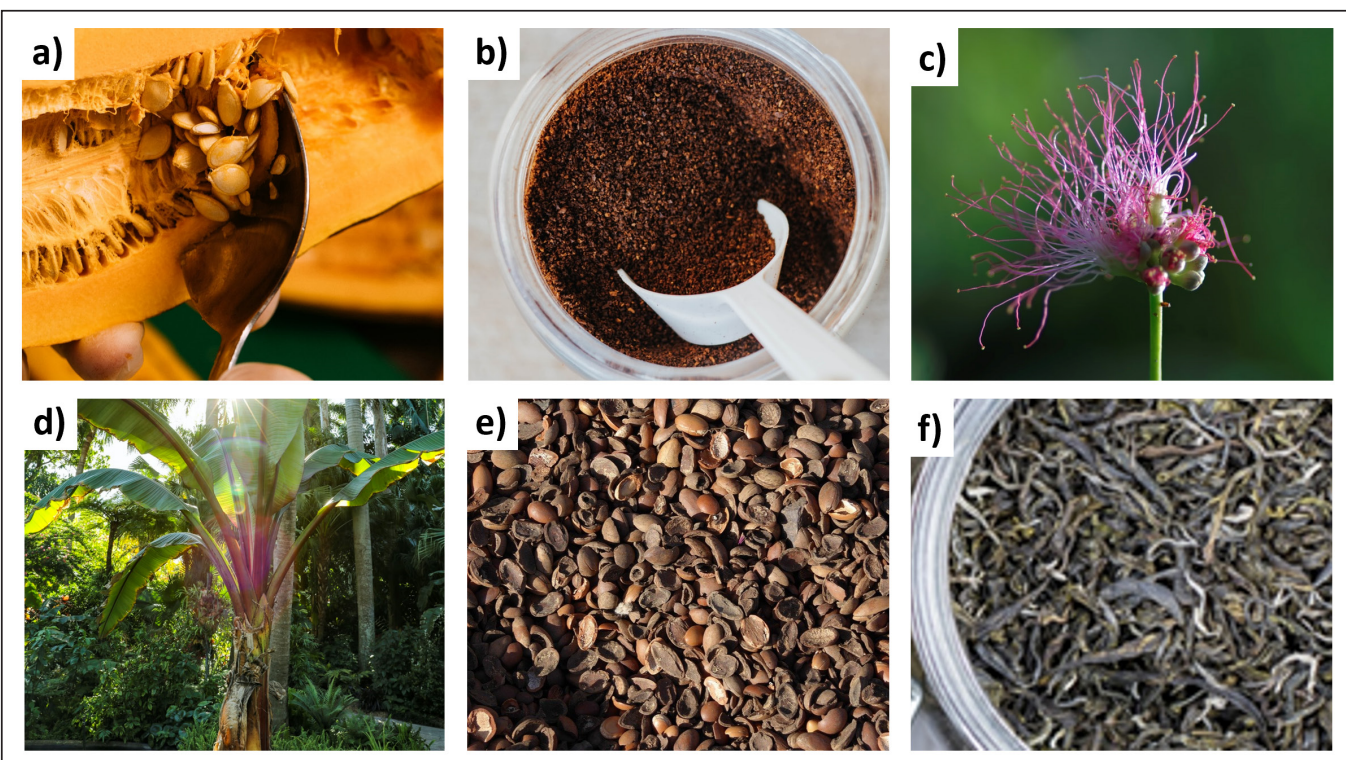

Figure 4. a) Cucumis melo, b) coffee grounds, c) Albizzia flowers, d) Banana fibers, e) Argan seed shells, and f) Waste tea leaves

Peng et al. (2013) extracted carbon from waste tea leaves (WTL), and the images in Figure 5 show the process involved in the synthesis of activated carbon. Five types of WTL were used to prepare AC, and the recovery process started with soaking the dried tea leaves in boiling water until room temperature. The WTL was then pyrolyzed at $600^{\circ} \mathrm{C}$ for $2 \mathrm{~h}$ with argon flow to produce carbonated products. Next, chemical activation was conducted using $\mathrm{KOH}$ solution followed by evaporation at $80^{\circ} \mathrm{C}$ in a vacuum. The dried carbonized product was then heated at $800^{\circ} \mathrm{C}$ for one $\mathrm{h}$ in an argon atmosphere and was further neutralized using $1 \mathrm{M} \mathrm{HCl}$ solution (Peng et al., 2013). The highest specific capacitance achieved was $330 \mathrm{~F} / \mathrm{g}$ at $1 \mathrm{~A} / \mathrm{g}$ from the electrode fabricated from WTL AC.

Another study with a similar method was conducted using Albizzia flowers (AF) as a precursor, and the process is shown in Figure 6. The carbonization process was done on the dried AFs at $600^{\circ} \mathrm{C}$ at a rate of $3^{\circ} \mathrm{Cmin}^{-1}$ for three $\mathrm{h}$ in an argon gas atmosphere. It was

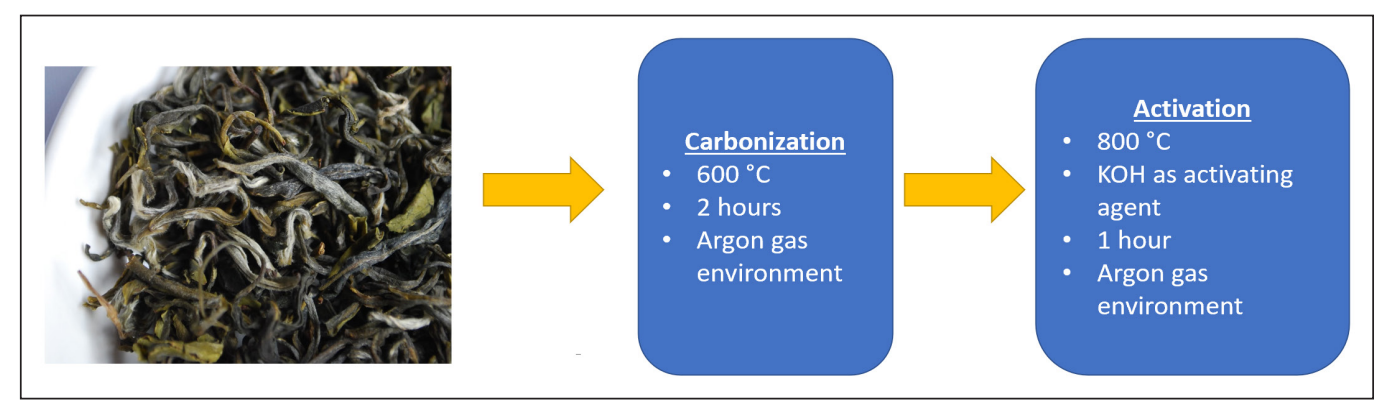

Figure 5. Two-step synthesis of activated carbon from waste tea leaves (Peng et al., 2013) 
followed by an activation process using $\mathrm{KOH}$ with a ratio of 1:3, $\mathrm{KOH}$ : Precarbonized AF (PCAF). The activation temperature used was 700,800 , or $900^{\circ} \mathrm{C}$ at a rate of $5^{\circ} \mathrm{C} \mathrm{min}-{ }^{1}$. The achieved activated samples were washed with $1 \mathrm{M} \mathrm{HCL}$ and deionized water until $\mathrm{Ph}$ 7 before it was dried at $80^{\circ} \mathrm{C}$ for ten $\mathrm{h}$. The fabricated electrode produced $406 \mathrm{~F} / \mathrm{g}$ at 0.5 $\mathrm{A} / \mathrm{g}$ in a $6 \mathrm{M} \mathrm{KOH}$ electrolyte (Wu et al., 2019).

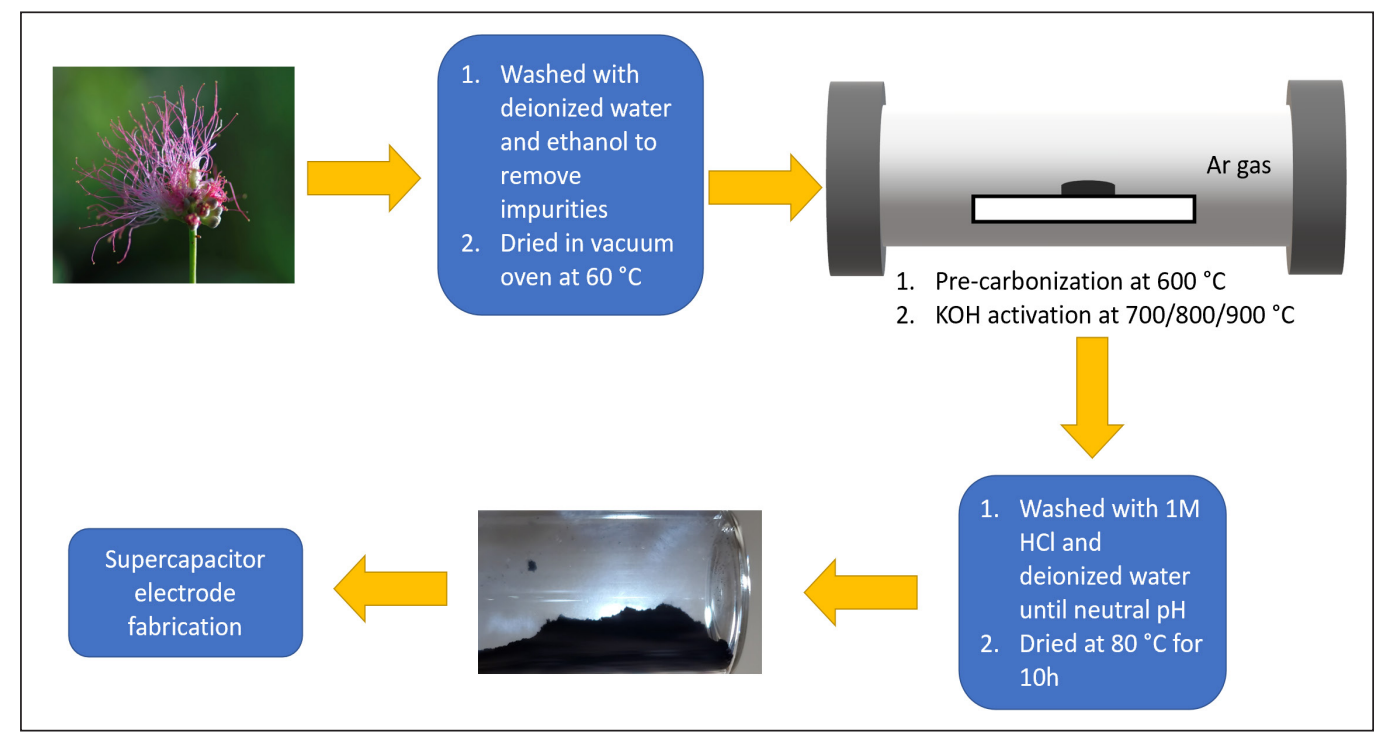

Figure 6. Process of preparing activated carbon from Albizzia flowers (Wu et al., 2019)

Apart from that, activated carbon from oil palm kernel shells (PKS) was synthesized by Misnon et al. (2015) to observe the effects of the activation method. Recycling PKS for value-added products is useful as they are abundantly available. This work used two types of activation methods: chemical activation by $\mathrm{KOH}$ and physical activation using steam. The PKS was pyrolyzed in a furnace for four $\mathrm{h}$ at $500^{\circ} \mathrm{C}$, under an oxygen deficit environment. Activated carbon was then produced through chemical activation (AC-C) and physical activation (AC-P). In chemical activation, Pyrolyzed carbon was stirred with $\mathrm{KOH}$ in the ratio of $1: 4$ for four $\mathrm{h}$ at $100^{\circ} \mathrm{C}$. Another sample was prepared using physical activation through steam. Both samples were then heated in a furnace at $500^{\circ} \mathrm{C}$ for four $\mathrm{h}$ and subsequently washed in $1 \mathrm{M} \mathrm{HCl}$ followed by distilled water until $\mathrm{pH}$ was neutral before they were further tested as electrodes (Misnon et al., 2015). AC-C and AC-P-based supercapacitor electrodes produced a capacitance of $210 \mathrm{~F} / \mathrm{g}$ and $123 \mathrm{~F} / \mathrm{g}$ at $0.5 \mathrm{~A} / \mathrm{g}$, respectively in $1 \mathrm{M} \mathrm{KOH}$ (Misnon et al., 2015).

Other than two-step synthesis, which is carbonization followed by activation, there is also a one-step synthesis whereby activation and carbonization are done simultaneously. Figure 7 illustrates the difference between one and two-step synthesis. 


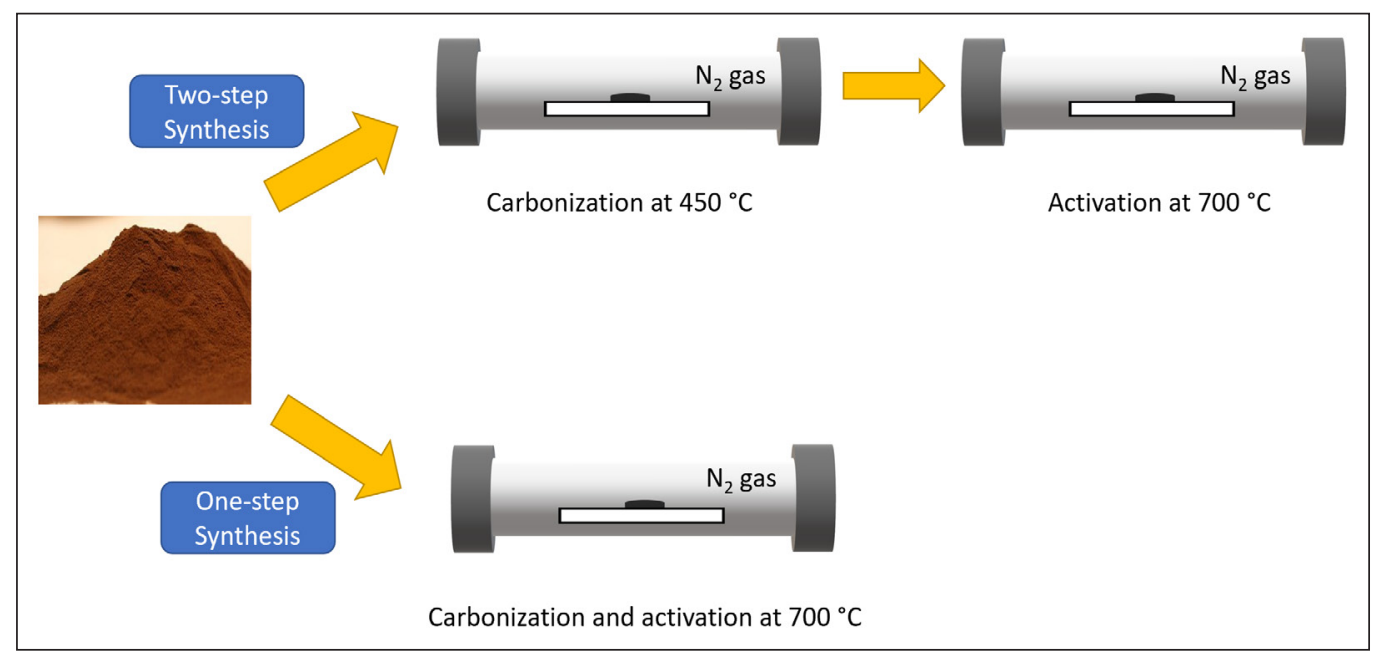

Figure 7. The process of one-step and two-step synthesis of activated carbon (Chiu \& Lin, 2019)

One-step synthesis was done to recover carbon from waste coffee grounds and studied the effects of different activation agents on the structural properties of the activated carbon (Chiu \& Lin, 2019). First, they dispersed waste coffee grounds in $1 \mathrm{M} \mathrm{KOH}$ and stirred for 6 hours. It was followed by washing the prepared powder with deionized water and subsequently drying it in a vacuum oven. Next, the dried powder was dispersed in aqueous solutions containing activating agents and stirred for $15 \mathrm{~min}$ during the activation process. The resultant solution was filtered, and the prepared powders were then annealed at $700^{\circ} \mathrm{C}$ in $\mathrm{N}_{2}$ for two h. The $\mathrm{KOH}$-activated carbon electrode from coffee grounds resulted in a specific capacitance of $19.28 \mathrm{~F} / \mathrm{g}$ and obtained the highest energy density of $6.94 \mathrm{Wh} / \mathrm{kg}$ at the power density of $350 \mathrm{~W} / \mathrm{kg}$ (Chiu \& Lin, 2019).

Jiang et al. (2013) demonstrated ginkgo shells to produce AC for supercapacitor application. The partially graphitized ginkgo-based activated carbon (GGAC) was prepared by pyrolysis, activation process using $\mathrm{KOH}$, and heat treatment with cobalt nitrate as graphitization catalyst. Ginkgo shell-based activated carbon preparation was initiated by drying the ginkgo shells at $60^{\circ} \mathrm{C}$ for $24 \mathrm{~h}$. The dried ginkgo shells were then pyrolyzed at $600^{\circ} \mathrm{C}$ at a rate of $10^{\circ} \mathrm{Cmin}^{-1}$ under nitrogen atmosphere for one $\mathrm{h}$ in a tube furnace. Finally, the pyrolyzed ginkgo shells were mixed with $\mathrm{KOH}$ at a ratio of 1:2 and heattreated in a nitrogen gas environment for one $\mathrm{h}$ at $700^{\circ} \mathrm{C}$. The HCL was used to neutralize the carbonized sample and subsequently rinsed using deionized water a few times until neutral $\mathrm{pH}$ was achieved. The product was denoted as ginkgo shell-based activated carbon (GAC). The authors used the same method to produce graphitized ginkgo-based activated carbon (GGAC), with an additional step to impregnate the GAC using cobalt nitrate in a diluted solution form. The GAC was impregnated for $12 \mathrm{~h}$ and subsequently heated treated at $900^{\circ} \mathrm{C}$ at a rate of $10^{\circ} \mathrm{Cmin}^{-1}$ for two $\mathrm{h}$. The findings showed a specific capacitance of 
$178 \mathrm{~F} / \mathrm{g}$ at a potential scan rate of $500 \mathrm{mV} / \mathrm{s}$ for GGAC, which is significantly higher than commercial activated carbons and ordered mesoporous carbons (Jiang et al., 2013).

Activated carbons from natural fibers are cost-effective. Hence, they have a great advantage in producing electrodes for supercapacitor applications. Simple pyrolysis and activation can produce activated carbon from cheap biomass sources like the Paulownia flower (PF). The PF is a widely planted flower in China and is ample with volatile oil and pharmaceutical materials. Generally, PF is disposed of and left to rot without further utilization. For the recovery of activated carbon, the matured PF was collected after it had fallen from Paulownia trees. The PF was pyrolyzed for two h at $600^{\circ} \mathrm{C}$ under a nitrogen atmosphere. The activation process took place after pyrolysis, whereby the carbonized Paulownia flower (PFC) was mixed with $\mathrm{KOH}$ as an activating agent. In this work, the PFC was mixed with different ratios of $2: 1,3: 1$, or $4: 1$ to the KOH to study the effect of activation agent concentration on the properties of supercapacitors. After mixing with $\mathrm{KOH}$, the mixture was further pyrolyzed at $800^{\circ} \mathrm{C}$ in a nitrogen atmosphere for one $\mathrm{h}$. The activated Paulownia flower was washed with $1 \mathrm{M} \mathrm{HCl}$ followed by deionized water until neutral $\mathrm{pH}$ was achieved. Electrodes were fabricated using the activated carbon from PF by mixing it with active materials, acetylene black, and polytetrafluoroethylene binder in the percentage of $85 \mathrm{mw} \%, 10 \mathrm{mw} \%$, and $5 \mathrm{mw} \%$, respectively. The supercapacitors were formed via sandwiching hydrophilic cellulose separator between two identical electrodes and immersed in $1 \mathrm{M} \mathrm{H}_{2} \mathrm{SO}_{4}$ electrolyte The symmetric supercapacitor based on a-PFC3 ( 3 mass ratios of $\mathrm{KOH}$ ) resulted in a specific capacitance of $297 \mathrm{~F} / \mathrm{g}$ at a current density of $1 \mathrm{~A} / \mathrm{g}$ within a potential range of 2-3V (Chang et al., 2015).

Subramanian et al. (2007) conducted another study on the electrochemical performance of supercapacitor electrode material using activated carbon from banana fibers. First, they have started to synthesize the activated carbon by washing and drying the banana fibers. Next, they have treated the fibers using $\mathrm{KOH}$ or $\mathrm{ZnCl}_{2}$ at $110^{\circ} \mathrm{C}$ for five days. The ratio of banana fiber to activating agent was 1:5. After treatment with the activation agent, the samples were pyrolyzed for one $\mathrm{h}$ at $800^{\circ} \mathrm{C}$ with a heating rate of $10^{\circ} \mathrm{C} / \mathrm{min}$ in a nitrogen gas atmosphere. The obtained AC was mixed with $20 \mathrm{wt} \%$ of carbon black and five wt $\%$ PVdF using NMP as a solvent to form a slurry. The slurry was then coated onto Ni mesh using the brush coating method. After drying for $30 \mathrm{~min}$ at $110^{\circ} \mathrm{C}$, the mesh was pressed to cohere the active electrode material to the Ni mesh thoroughly.

The coated Ni mesh was used as a working electrode, saturated calomel electrode as reference electrode, and PT wire was used as a counter electrode during the electrochemical performance test. From CV and GCD studies, the highest specific capacitance has produced the sample produced using $\mathrm{ZnCl}_{2}$ as an activating agent with the capacitance of $74 \mathrm{~F} / \mathrm{g}$ at $0.5 \mathrm{~A} / \mathrm{g}$ in $1 \mathrm{M} \mathrm{Na}_{2} \mathrm{SO}_{4}$ electrolyte. In addition, $88 \%$ of Coulombic efficiency was exhibited by this sample after $500 \mathrm{Cycles}$ at $0.5 \mathrm{~A} / \mathrm{g}$. On the other hand, $\mathrm{KOH}$ treated AC produced a 
capacitance of $66 \mathrm{~F} / \mathrm{g}$ at $0.5 \mathrm{~A} / \mathrm{g}$. The BET surface area of $\mathrm{ZnCl}_{2}$ and $\mathrm{KOH}$ treated activated carbons are $1097 \mathrm{~m}^{2} / \mathrm{g}$ and $686 \mathrm{~m}^{2} / \mathrm{g}$, respectively (Subramanian et al., 2007).

\section{EFFECTS OF ACTIVATION TEMPERATURE ON ELECTROCHEMICAL PERFORMANCE}

The performance of activated carbon can be significantly enhanced under appropriate conditions. The initial step in producing activated carbon is carbonization to produce char from the pyrolysis process. Throughout the process, moisture and volatile compounds are removed from the biomass (Ioannidou \& Zabaniotou, 2007). The AC can be synthesized using physical and chemical activation after the carbonization process. Physical activation is generally done with gas activating agents, such as $\mathrm{CO}_{2}$ and steam, while chemical activation involves chemical agents, such as acid, metal oxide, and alkali metal. The activation process finally results in activated carbon with a large surface area, high porosity, and high pore volume (Nor et al., 2013).

Teo et al. (2016) used rice husk as a precursor for AC, and the surface area was studied in detail. The authors varied the activation temperatures and compared the findings with the current data similar to their work. The study also portrayed current studies on the effects of activation temperature on mesopores and micropores of the $\mathrm{AC}$, as shown in Table 1 . The rice husk $(\mathrm{RH})$ was treated with $1 \mathrm{M} \mathrm{NaOH}$ for $24 \mathrm{~h}$ at room temperature and was subsequently dried in the oven. The carbonization was done on the RH in a furnace for four $\mathrm{h}$ at $400^{\circ} \mathrm{C}$. Silica traces were removed from the carbonized rice husk (RHC) by mixing the RHC with $1 \mathrm{M} \mathrm{NaOH}$ solution for 20 minutes to achieve a purer form of $\mathrm{RHC}$. The activation process was initiated by impregnating $\mathrm{RHC}$ with $\mathrm{KOH}$. The mass ratio used for the activation process was 1:5 (RHC: $\mathrm{KOH})$, and the mixture was stirred for 30 minutes before leaving it to dry overnight at $100^{\circ} \mathrm{C}$. After drying, the mixture was activated at different temperatures, which were $750^{\circ} \mathrm{C}, 850^{\circ} \mathrm{C}$, and $950^{\circ} \mathrm{C}$ in a nitrogen gas atmosphere. Then, the achieved activated carbon was washed until neutral $\mathrm{pH}$ was achieved (Teo et al., 2016).

The results indicated that samples activated at higher activation temperatures were porous. However, it must be noted that porosity is an important factor in the production

Table 1

Raman spectral values of current studies on activated carbon with different activation temperatures (Teo et al., 2016)

\begin{tabular}{lccccc}
\hline Sample & $\mathbf{S}_{\text {BET }}\left(\mathbf{m}^{2} \mathbf{g}^{-1}\right)$ & $\begin{array}{c}\mathbf{V}_{\text {pore }}(\text { Total) } \\
\left(\mathbf{c m}^{3} \mathbf{g}^{-1}\right)\end{array}$ & $\begin{array}{c}\mathbf{V}_{\text {pore }}(\mathbf{m i c r o}) \\
\left(\mathbf{c m}^{\mathbf{3}} \mathbf{g}^{-1}\right)\end{array}$ & $\begin{array}{c}\mathbf{V}_{\text {pore }}(\mathbf{m e s o}) \\
\left(\mathbf{c m}^{\mathbf{3}} \mathbf{g}^{-1}\right)\end{array}$ & $\begin{array}{c}\text { t-plot micropore area } \\
\left(\mathbf{m}^{2} \mathbf{g}^{-1}\right)\end{array}$ \\
\hline AC750 & 2121 & 1.022 & 0.589 & 0.243 & 1426 \\
AC850 & 2696 & 1.496 & 0.274 & 0.691 & 486 \\
AC950 & 1592 & 1.293 & 0.052 & 1.056 & - \\
\hline
\end{tabular}

Note: $\mathrm{S}_{\mathrm{BET}}$, Brunauer-Emmett-Teller (BET) surface area, $\mathrm{V}_{\text {pore, }}$ pore volume 
of activated carbon as it would improve the specific capacitance of the supercapacitor electrodes. Nonetheless, AC850 with the largest BET surface area produced the highest specific capacitance of $147 \mathrm{~F} / \mathrm{g}$ at $0.1 \mathrm{~A} / \mathrm{g}$.

Another investigation was carried out for supercapacitor application using argan seed shells. Argan tree is regularly found in Morocco in the southwest region, and the plant seeds are commonly used to extract oil for cosmetic and culinary uses. A large quantity of argan seed shells (ASS) residues were produced during the oil extraction. The ASS was collected and carbonized for three $\mathrm{h}$ at $500^{\circ} \mathrm{C}$ under a nitrogen gas atmosphere. After carbonization, chemical activation was done using $\mathrm{KOH}$. The ratio for chemical activation used was 1: 4 (sample: $\mathrm{KOH}$ ). After chemical activation, the samples were heated for $12 \mathrm{~h}$ at $60^{\circ} \mathrm{C}$; then, the temperature was increased to $110^{\circ} \mathrm{C}$ to dry the sample. The process was followed by pyrolysis at $300^{\circ} \mathrm{C}$ for two h. Then, the temperature was increased to $800^{\circ} \mathrm{C}$ for three $\mathrm{h}$ at the rate of $10^{\circ} \mathrm{Cmin}^{-1}$. In the final stage, the prepared activated carbon was washed using $0.1 \mathrm{M} \mathrm{HCl}$ then rinsed using deionized water until no chloride ions were detected (Elmouwahidi et al., 2012). The electrochemical studies were conducted in three electrodes setups with $1 \mathrm{M} \mathrm{H}_{2} \mathrm{SO}_{4}$ as electrolyte. The highest capacitance achieved was $355 \mathrm{~F} / \mathrm{g}$ at $125 \mathrm{~mA} / \mathrm{g}$, while the highest retention was $93 \%$ at $1 \mathrm{~A} / \mathrm{g}$.

Another potential precursor of activated carbon used in supercapacitor application is oil palm empty fruit bunches that have been studied by Farma et al. (2013). The advantage of using oil palm empty bunches is that it is abundantly available in Malaysia as the oil palm industry is one of the major agricultural sectors in Malaysia. The industry mainly focuses on producing cooking oil from oil palm fruits. During this process of extracting oil, many empty fruit bunches (EFB) were produced and could potentially pollute the environment without a proper disposal method. The burning of EFB for the production of fertilizers is also creating environmental hazards by emitting greenhouse gases from combustion. Therefore, in their study, the EFB was used as a raw material to produce monolithic nanoporous activated carbon for supercapacitor electrodes (Farma et al., 2013). The authors made some comparisons on the specific capacitance achieved with other types of precursors, as presented in Table 2 .

The conversion of EFB to activated carbon was initiated by pre-carbonization of EFB fibers at a low temperature of $280^{\circ} \mathrm{C}$. It was followed by ball milling for $18 \mathrm{~h}$ and subsequently sieved to obtain self-adhesive carbon grains (SACG) powder. The SACG was mixed with $\mathrm{KOH}$ in wet conditions using distilled water and stirred for one $\mathrm{h}$ to obtain a homogeneous mixture. Green monoliths (GMs) of the SACG and green monolith (GMK) of the $\mathrm{KOH}$-treated SACG were prepared in a mold before it was further carbonized in a nitrogen gas environment at $800^{\circ} \mathrm{C}$ at a rate of 1.5 liters per minute (Farma et al., 2013).

Elaiyappillai et al. (2019) recovered precursor for AC from Cucumis melo (Cm) fruit peel by adapting two stages method (carbonization and activation). First, the $\mathrm{Cm}$ 
Table 2

Comparison of specific capacitance between other precursors (Farma et al., 2013)

\begin{tabular}{lccc}
\hline Biomass precursor & Activation method & $\mathbf{S}_{\mathbf{B E T}}\left(\mathbf{m}^{\mathbf{2}} \mathbf{g}^{-1}\right)$ & $\mathbf{C}_{\text {sp }}\left(\mathbf{F g}^{-1}\right)$ \\
\hline Firewood & $\mathrm{KOH}$ & 2821 & 95 \\
Coffee bean waste & $\mathrm{ZnCl}_{2}$ & 1019 & 368 \\
Cherry stones & $\mathrm{KOH}$ & 1624 & 174 \\
Coffee shell & $\mathrm{ZnCl}$ & 156 \\
Recycled wastepaper & $\mathrm{KOH}$ & 842 & 180 \\
Cassava peel waste & $\mathrm{KOH}+\mathrm{CO}_{2}$ & 417 & 153 \\
Sugar cane bagasse & $\mathrm{ZnCl}{ }_{2}$ & 1352 & 300 \\
Apricot shell & $\mathrm{NaOH}$ & 1788 & 348 \\
Coffee endocarp & $\mathrm{CO}_{2}$ & 2335 & 176 \\
Sunflower seed shell & $\mathrm{KOH}_{2}$ & 709 & 311 \\
Rubber wood sawdust & $\mathrm{CO}_{2}$ & 2509 & 138 \\
Argan seed shell & $\mathrm{KOH}_{2}$ & 912 & 355 \\
Camellia olleifera shell & $\mathrm{ZnCl}_{2}$ & 2062 & 374 \\
Poplar wood & $\mathrm{HNO}_{3}$ & 1935 & 234 \\
Fibers of palm oil empty fruit bunches & $\mathrm{KOH}^{2} \mathrm{CO}_{2}$ & 416 & 149 \\
\hline
\end{tabular}

was heated for four $\mathrm{h}$ at $300^{\circ} \mathrm{C}$ at a rate of $5^{\circ} \mathrm{Cmin}^{-1}$ under vacuum conditions. Then, the sample was left to cool to room temperature before being crushed into fine powder form (Elaiyappillai et al., 2019). In the second stage, $\mathrm{KOH}$ was used for chemical activation. The authors varied the activation temperature from $600-900^{\circ} \mathrm{C}$, and samples were heated for three $\mathrm{h}$. The activated carbon from $\mathrm{Cm}-900$ produced the highest specific capacitance of $404 \mathrm{~F} / \mathrm{g}$ at $1 \mathrm{~A} / \mathrm{g}$ with $1 \mathrm{M} \mathrm{KOH}$ as electrolyte. As a result, the power density of Cm-900 was $279.78 \mathrm{w} / \mathrm{kg}$, whereas the energy density was $29.30 \mathrm{Wh} / \mathrm{kg}$. Meanwhile, the charge retention obtained after 8000 cycles of charge/discharge was $91 \%$.

Research by Cheng et al. (2020) produced AC from Laminaria japonica, a type of seaweed known as brown algae plant and mostly grown on ropes in the sea between Korea and Japan. The synthesis of AC was done using two steps syntheses; pre-carbonization followed by activation using $\mathrm{KOH}$. The varied carbonization temperature was $600^{\circ} \mathrm{C}$, $800^{\circ} \mathrm{C}, 1000^{\circ} \mathrm{C}$ and $1200^{\circ} \mathrm{C}$. Most of the previous studies chose activation temperature as the manipulated variable to study its effects on the characteristics of the activated carbon produced. After pre-carbonization, the mixture was activated at $700^{\circ} \mathrm{C}$ and $800^{\circ} \mathrm{C}$ under a nitrogen gas atmosphere for two $\mathrm{h}$ and subsequently neutralized using $1 \mathrm{M}$ HCL solution and deionized water (Cheng et al., 2020). The overall process is shown in Figure 8. The specific capacitance of the supercapacitor electrode fabricated from L. japonica activated carbon was $192 \mathrm{~F} / \mathrm{g}$ at $0.1 \mathrm{~A} / \mathrm{g}$, and the electrode exhibited almost $100 \%$ of capacitance retention after 10000 cycles at $1 \mathrm{~A} / \mathrm{g}$. 


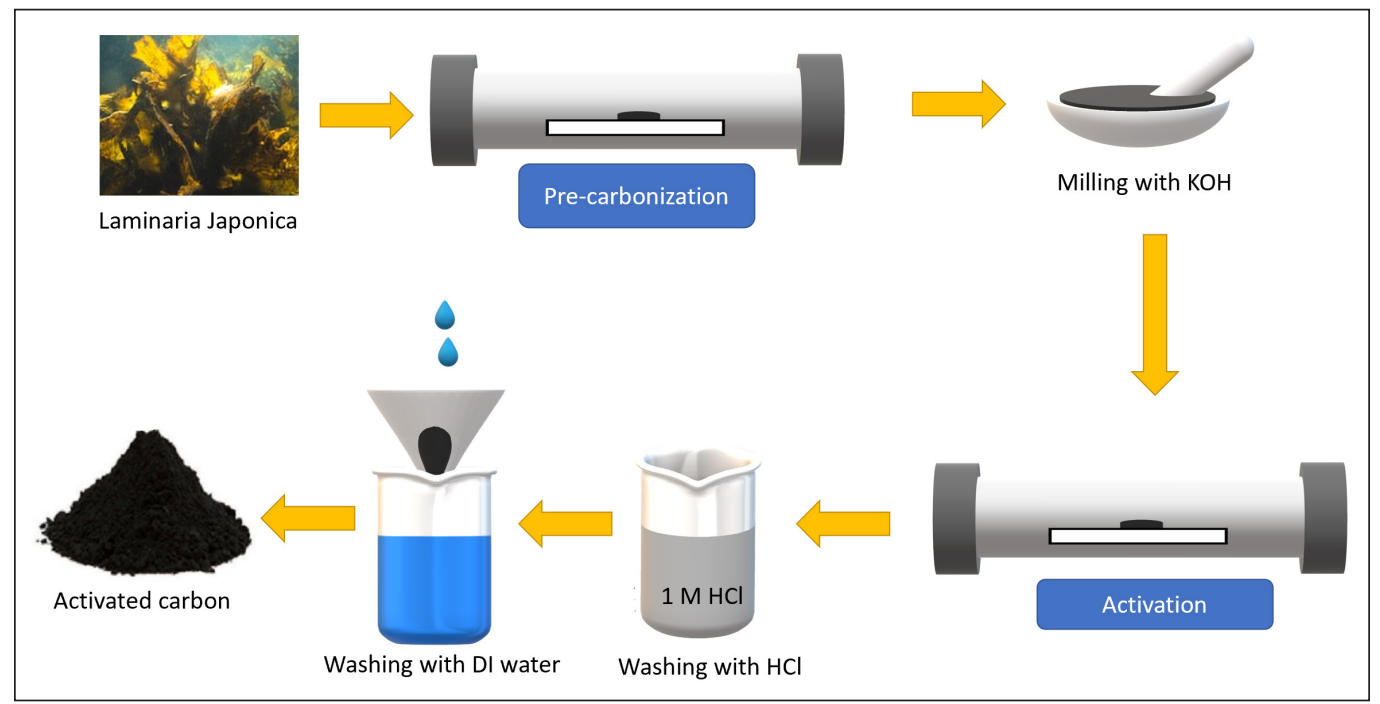

Figure 8. Synthesis of activated carbon from L. japonica (Cheng et al., 2020)

Another precursor was discovered from Saccharum spontaneum by Samantray and Mishra (2019), containing 48.91\% of carbon, as shown in Table 3. Zinc chloride was used as the activating agent in a one-step synthesis process with precursor ratio to the activating agent, 0.5:1. The carbonization temperature used was $400^{\circ} \mathrm{C}$ to $600^{\circ} \mathrm{C}$ under a nitrogen gas environment. After carbonization, the samples were neutralized using $0.1 \mathrm{M} \mathrm{HCl}$ solution and deionized water. Figure 9 shows the flow chart of activated carbon synthesis. The results from Taguchi analysis in this research prove that
Table 3

Analysis of S. spontaneum (Samantray \& Mishra, 2019)

\begin{tabular}{lc}
\hline \multicolumn{1}{c}{ Analysis } & Stem \\
\hline Proximate (wt\%) & \\
Moisture & 9 \\
Volatile matter & 72 \\
Ash & 3 \\
Fixed carbon & 16 \\
Ultimate (wt\%) & \\
Carbon & 48.910 \\
Hydrogen & 8.341 \\
Nitrogen & 0.905 \\
Sulfur & 0.18 \\
Oxygen & 41.664 \\
\hline
\end{tabular}
optimal conditions to produce high surface area carbon are $600^{\circ} \mathrm{C}$, chemical ratio of 1 and 60 min holding time for carbonization process (Samantray \& Mishra, 2019).

\section{CHARACTERIZATION OF ACTIVATED CARBON-BASED SUPERCAPACITOR ELECTRODE}

The commonly used method for characterization of activated carbon is X-ray diffraction (XRD), Field Emission Scanning Electron Microscopy (FE-SEM), Transmission electron microscopy (TEM), Fourier Transform Infrared Spectroscopy (FTIR), Raman spectroscopy, and Brunauer-Emmett-Teller (BET) surface area (Tobi et al., 2019). Meanwhile, the 


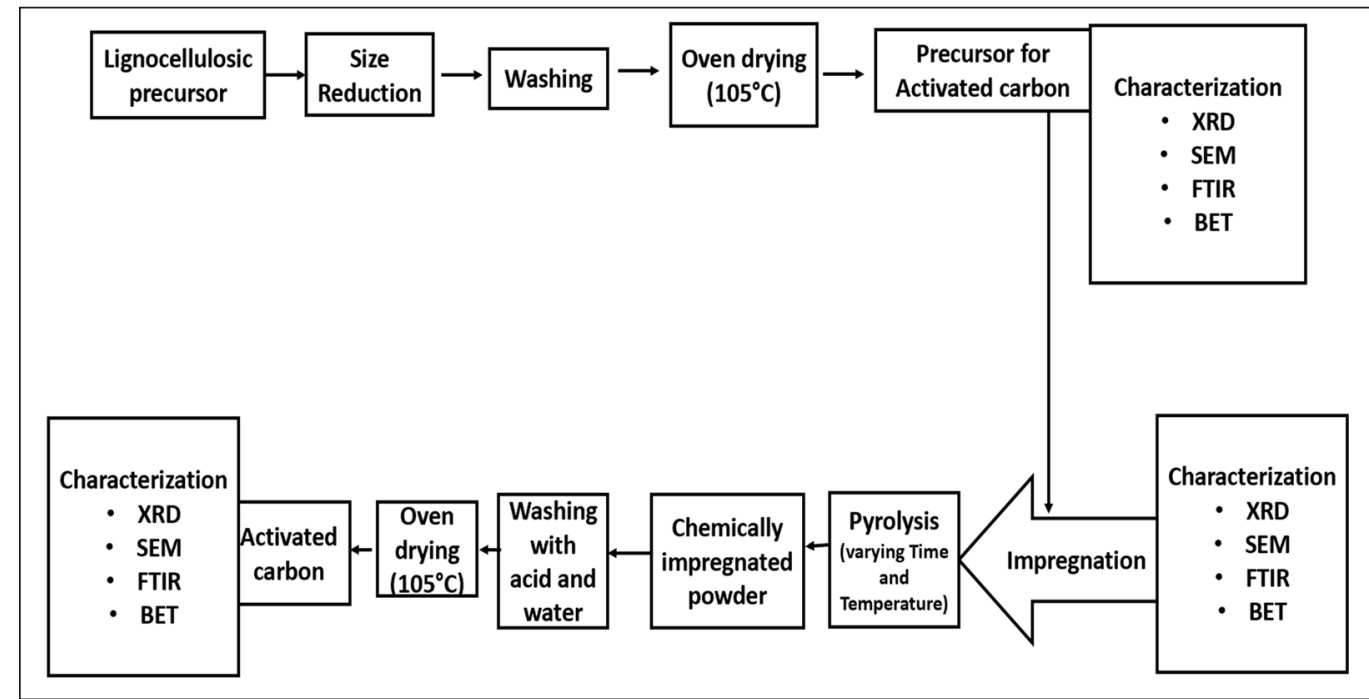

Figure 9. Activated carbon synthesis from S. spontaneum (Samantray \& Mishra, 2019).

common electrochemical properties are characterized by using Cyclic Voltammetry (CV), galvanostatic charge/discharge (GCD), and electrochemical impedance spectroscopy (EIS).

$\mathrm{KOH}$ activation and phosphoric acid-treated carbon derived from the banana stem were compared with other hard carbons derived from corn cob and potato starch. From Raman spectroscopy of these four carbons, it was noted that partial graphitization is observed on all these samples. $\mathrm{KOH}$ activated banana stem (KHC) has a more disordered nature. For energy storage applications using carbon, this disordered nature is advantageous owing to the existence of active surfaces. SEM of KHC, phosphoric acid-treated banana stem (PHC), and corn-cob derived carbon (CHC), as shown in Figures 10 (a), (b), and (c), respectively, shows more visible porous structure compared to potato starch derived carbon (SHC), which did not show any evidence of porosity, based on the SEM images as shown in Figure 10 (d). Similar to the conclusions made with SEM, TEM images additionally show that the pore diameters are in the nanometer range except for SHC. When the carbonization temperatures were increased, a greater amount of micro range crystallites were present by various carbon layers. In addition, the micropores and mesopores facilitate the charge

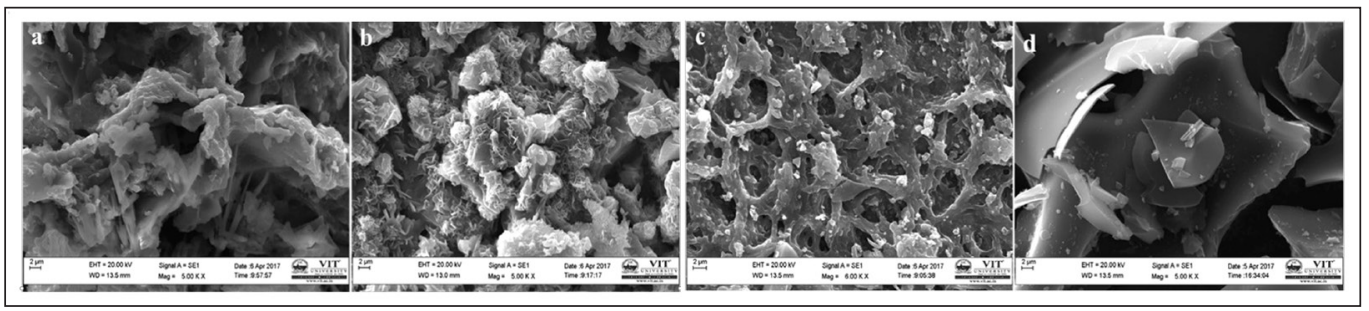

Figure 10. FE-SEM images of (a) KHC, (b) PHC, (c) CHC and (d) SHC (Yao et al., 2015) 
transferring process in carbons and subsequently increase the electrochemical performance of the supercapacitor electrode fabricated.

Table 4 shows the specific capacitance achieved by these four samples with the BET surface area of each sample. Based on the BET surface area results, The larger surface area possessed by $\mathrm{KHC}$ and $\mathrm{CHC}$ attributes to improved performance of supercapacitors. $\mathrm{KHC}$ achieved the highest specific capacitance as the improved surface area, lower pore diameter and increased pore volume helped electrochemical performance. The improved surface area is caused by the pore diameter, which is about $1 \mathrm{~nm}$ as based on literature, better supercapacitor performance is achieved as the pore diameter is close to $1 \mathrm{~nm}$ (Chmiola et al., 2006; Yao et al., 2015).

Table 4

Specific capacitance with surface porosity analysis (Yao et al., 2015)

\begin{tabular}{lcccc}
\hline \multicolumn{1}{c}{ Sample } & $\begin{array}{c}\text { Specific } \\
\text { Capacitance }(\mathbf{F} / \mathbf{g})\end{array}$ & $\begin{array}{c}\text { BET Surface area } \\
\left(\mathbf{m}^{2} / \mathbf{g}\right)\end{array}$ & $\begin{array}{c}\text { Average pore } \\
\text { diameter }(\mathbf{n m})\end{array}$ & $\begin{array}{c}\text { Average pore } \\
\text { volume }(\mathbf{c c} / \mathbf{g m})\end{array}$ \\
\hline KHC & $479.23 @ 1 \mathrm{mV} / \mathrm{s}$ & 567.36 & 1.205 & 0.175 \\
$\mathbf{C H C}$ & $309.81 @ 2 \mathrm{mV} / \mathrm{s}$ & 215.42 & 1.199 & 0.107 \\
$\mathbf{P H C}$ & $202.11 @ 2 \mathrm{mV} / \mathrm{s}$ & 177.72 & 1.789 & 0.091 \\
SHC & $99.9 @ 2 \mathrm{mV} / \mathrm{s}$ & 42.43 & 1.363 & 0.099 \\
\hline
\end{tabular}

The CV curves, as shown in Figure 11, show evident redox peaks for all the samples in $6 \mathrm{M} \mathrm{KOH}$ electrolyte, especially by $\mathrm{KHC}$. These redox peaks indicate that faradaic reaction related to pseudocapacitance occurs during the charge/discharge process. The samples also exhibit EDLC behavior as the CV curves have quasi-rectangular shapes. These EDLC attributes are caused by the hydrophilic nature of the micro-ordered sheets

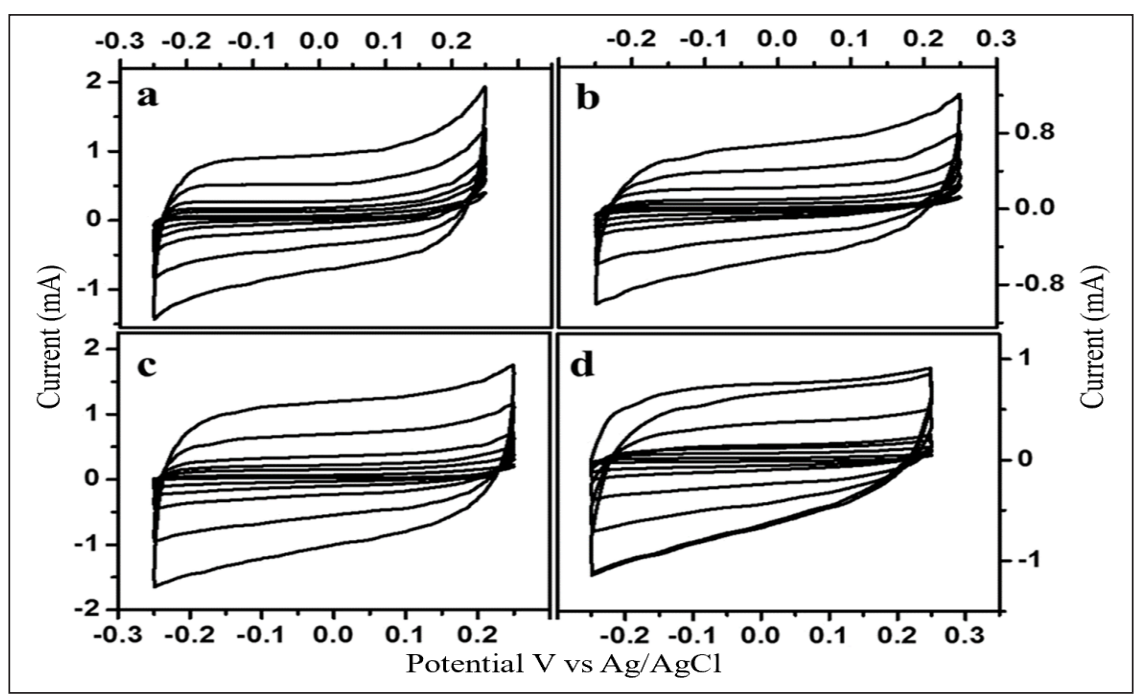

Figure 11. CV curves of (a) KHC, (b) PHC, (c) CHC and (d) SHC (Yao et al., 2015) 


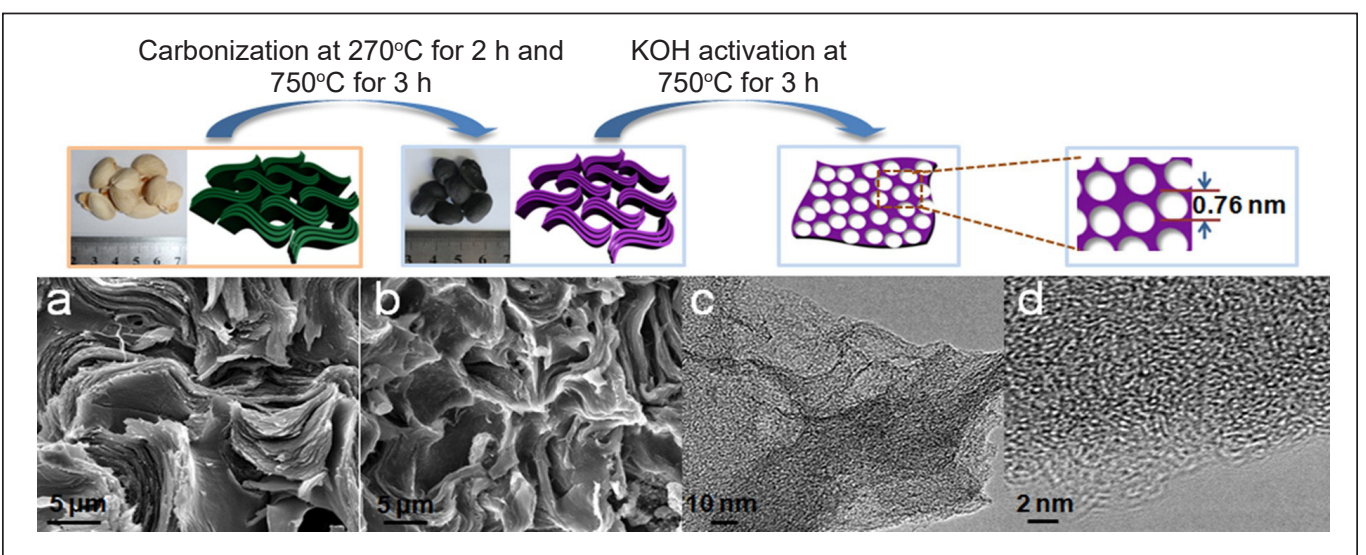

Figure 12. Process of synthesizing AC from pistachio nutshell with a)SEM of natural pistachio shell, b) SEM of C-SPN, c) and d) HRTEM of AC-SPN-3 at different magnification (Xu et al., 2014)

with oxygen on the edge of the structures. In the galvanostatic charge-discharge curve, the EDLC behavior causes a triangular shape, whereas the pseudocapacitance gives a smooth curvilinear shape nearing the triangle's peak (Yao et al., 2015).

Pistachio nutshell was activated at the different mass ratios with $\mathrm{KOH}$ as an activating agent with a pyrolysis temperature of $750^{\circ} \mathrm{C}$ (Xu et al., 2014). The samples were labeled as AC-SPN-X, where $\mathrm{X}$ denotes the mass ratio between $\mathrm{KOH}$ and carbonized pistachio nutshell (C-SPN). The process of

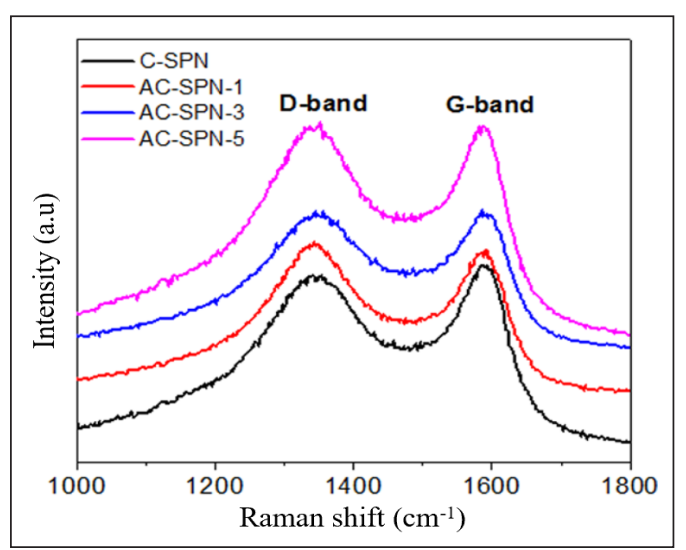

Figure 13. Raman spectroscopy of samples after $\mathrm{KOH}$ activation (Xu et al., 2014)

synthesizing activated carbon is described in Figure 12, together with the morphology of the sample at each stage. From the SEM analysis, C-SPN exhibits a 2D lamellar structure similar to a natural pistachio shell; however, some shrinkage is observed. From HRTEM analysis, AC-SPN-3 possesses interconnected porous structures with a $0.5-1 \mathrm{~nm}$ pore diameter. The Raman spectroscopy results shown in Figure 13 confirms that all the samples have defective graphitic structures as the peaks are present about $1320 \mathrm{~cm}^{-1}$ and $1580 \mathrm{~cm}^{-1}$ (Kim et al., 2011; Li et al., 2013; Shimodaira \& Masui, 2002). The degree of graphitization depends on the ratio of $\mathrm{I}_{\mathrm{G}}$ and $\mathrm{I}_{\mathrm{D}}$, which also indicates higher electrical conductivity with a higher ratio value (Bogeat, 2021; Dresselhaus et al., 2005; Mhamane et al., 2011).

Based on Nyquist plots, AC-SPN-3 exhibits the highest electrical conductivity among the other samples, which is supported by the relatively high $\mathrm{I}_{\mathrm{G}} / \mathrm{I}_{\mathrm{D}}$ value of AC-SPN-3 compared to AC-SPN-1 and AC-SPN-5. Hence, AC-SPN-3 has the most graphitic layers 
compared to other samples, although it has disordered carbon structures (Shimodaira \& Masui, 2002). From the CV curves of AC-SPN-3, as shown in Figure 14(a), a quasirectangular shape is observed. Furthermore, AC-SPN-3 has the highest specific capacitance of 313 and $215 \mathrm{~F} / \mathrm{g}$ in $6 \mathrm{M} \mathrm{KOH}$ and $\mathrm{TMABF}_{4}$ electrolytes, respectively, compared to other samples as shown in Figure 14(b).

Gupta et al. (2021) synthesized activated carbon from Desmostachya bipinnata (Kusha grass) and studied its electrochemical performance as a supercapacitor electrode (Gupta et al., 2021). The description of steps involved in the DP-AC synthesis is as shown in Figure 15. From the XRD and Raman spectroscopy, as shown in Figure 16, characteristics of activated carbon were confirmed, and an amorphous carbon structure is present (Ghosh
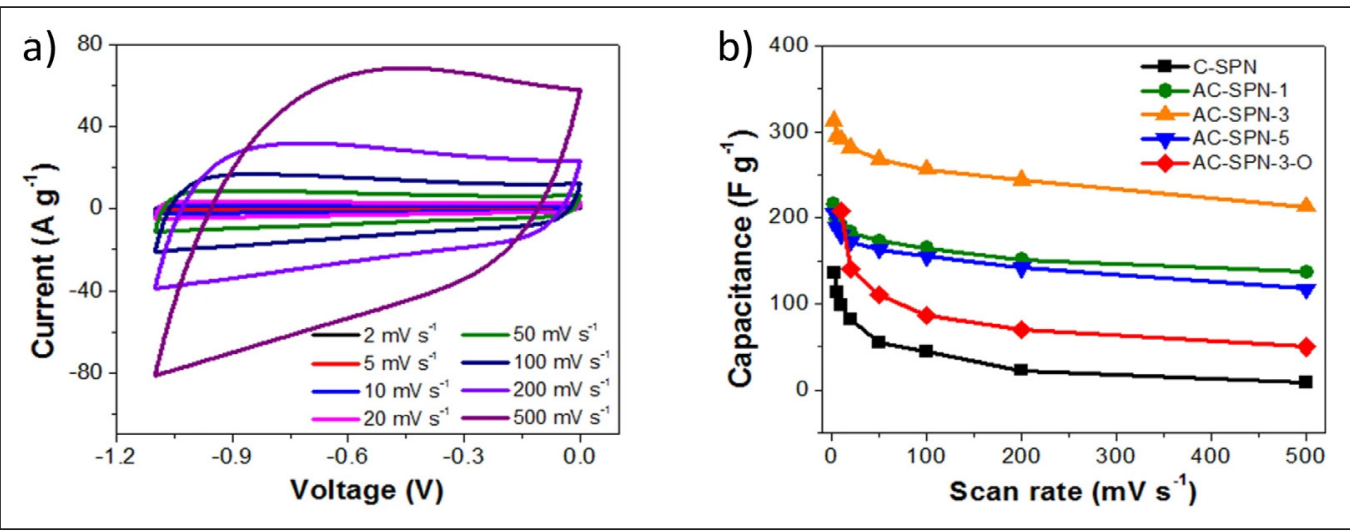

Figure 14. a) CV curve of AC-SPN-3 and b) Specific capacitance of all samples at different scan rates (Xu et al., 2014)

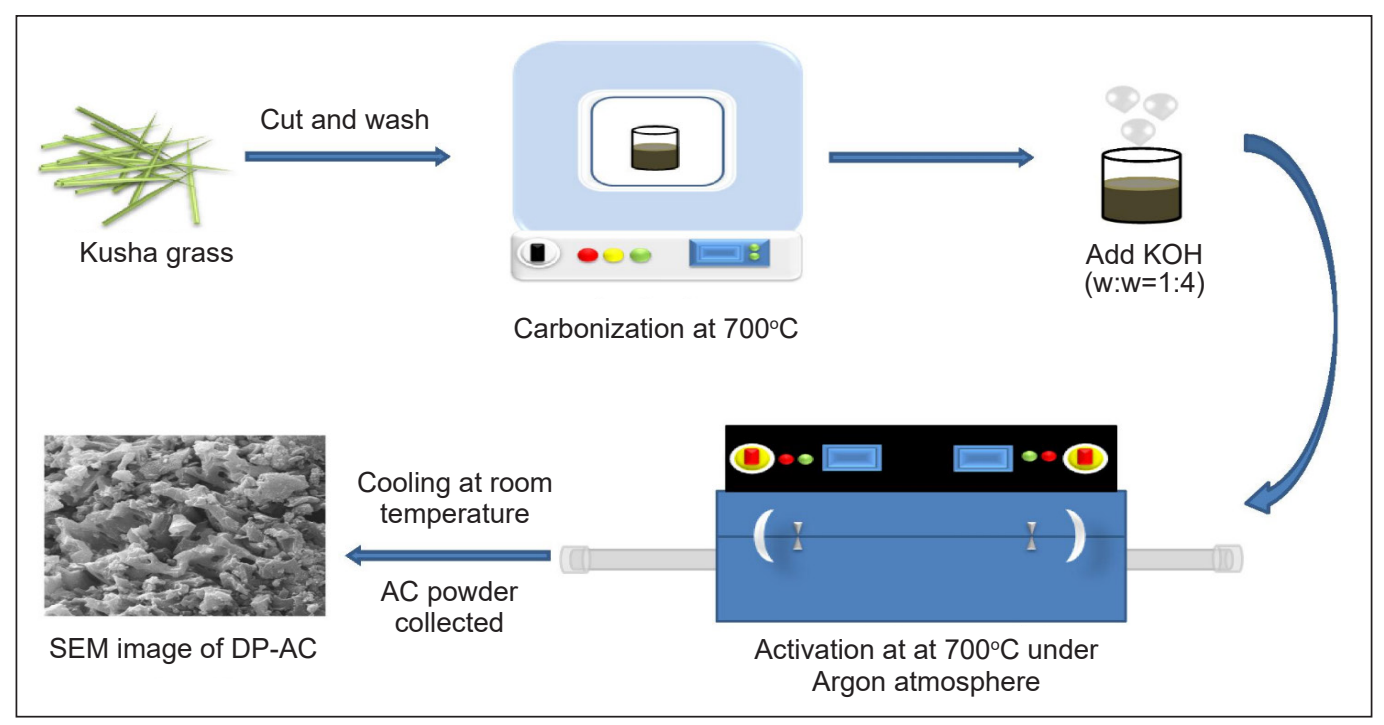

Figure 15. Synthesis of activated carbon from D. bipinnata (Gupta et al., 2021) 


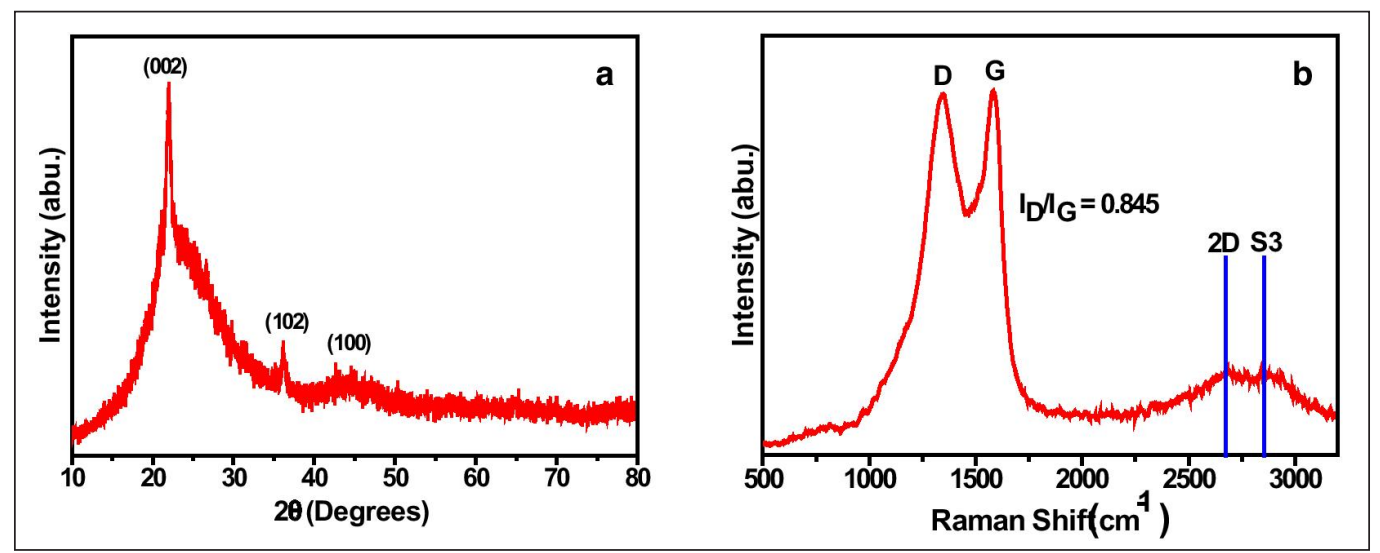

Figure 16. a) XRD pattern and b) Raman spectrum of DP-AC (Gupta et al., 2021)

et al., 2019; Pang et al., 2016). In Raman spectroscopy, the D peak is positioned at 1346 $\mathrm{cm}^{-1}$ and $\mathrm{G}$ Peak at $1587 \mathrm{~cm}^{-1}$. It proves activated carbon with graphitic structure and edge imperfection (Zhang et al., 2013). Another two peaks at $2678 \mathrm{~cm}^{-1}$ and $2840 \mathrm{~cm}^{-1}$ prove the existence of a few layered carbon materials (Purkait et al., 2017). From SEM analysis, it was observed that there is a large, disordered porous structure as a result of an etching by $\mathrm{KOH}$ during activation. The BET surface area of DP-AC is $738.56 \mathrm{~m}^{2} / \mathrm{g}$ with an average pore diameter of $3.3 \mathrm{~nm}$. The electrochemical study was performed in the three-electrode system with $6 \mathrm{M} \mathrm{KOH}$ as electrolyte. DP-AC achieved the highest specific capacitance of $220.7 \mathrm{~F} / \mathrm{g}$ at $10 \mathrm{mV} / \mathrm{s}$ from the CV study and $218 \mathrm{~F} / \mathrm{g}$ at $0.7 \mathrm{~A} / \mathrm{g}$ from the GCD study. A maximum energy density of $19.3 \mathrm{Wh} / \mathrm{kg}$ was achieved at a power density of $277 \mathrm{~W} / \mathrm{kg}$.

\section{CONCLUSION}

From the findings obtained in previous research works, it was found that there are various sources of carbon that can be converted to activated carbon and used for supercapacitors application. Most of the works used a similar method of activation and carbonization to prepare the AC. Some of the parameters that can be manipulated during the preparation of $\mathrm{AC}$ are activation temperature, type of activating agent, the ratio of activated carbon to the activating agent, and activation method. These parameters would vary the electrochemical properties of the electrode in terms of its specific capacitance and capacitance retention. The literature has shown a variety of materials synthesized from heterogeneous natural fiber precursors for supercapacitors based on carbon electrodes. An in-depth comparison has given some indications that natural fibers possess a high potential to be used for highperformance supercapacitor electrodes. Additional studies are essential to minimize the main knowledge gaps in the field of sustainable materials for energy storage applications. This review shows that relatively inexpensive and renewable resources from plants are 
highly porous carbon and can be converted into useful products, such as supercapacitors for energy storage applications, which are expected to be in great demand in the future.

\section{ACKNOWLEDGEMENT}

The authors would like to thank the College of Engineering, Universiti Tenaga Nasional (UNITEN), Kajang, Malaysia, and Yayasan Canselor UNITEN (YCU) for the research grant support through iRMC, Grant Number: 201901001 YCU.

\section{REFERENCES}

Afif, A., Rahman, S. M. H., Azad, A. T., Zaini, J., Islan, M. A., \& Azad, A. K. (2019). Advanced materials and technologies for hybrid supercapacitors for energy storage - A review. Journal of Energy Storage, 25, Article 100852. https://doi.org/https://doi.org/10.1016/j.est.2019.100852

Ahmed, M. B., Johir, M. A. H., Zhou, J. L., Ngo, H. H., Nghiem, L. D., Richardson, C., Moni, M. A., \& Bryant, M. R. (2019). Activated carbon preparation from biomass feedstock: Clean production and carbon dioxide adsorption. Journal of Cleaner Production, 225, 405-413. https://doi.org/10.1016/j.jclepro.2019.03.342

Arunachalam, S., Kirubasankar, B., Pan, D., Liu, H., Yan, C., Guo, Z., \& Angaiah, S. (2020). Research progress in rare earths and their composites based electrode materials for supercapacitors. Green Energy and Environment, 5(3), 259-273. https://doi.org/10.1016/j.gee.2020.07.021

Bogeat, A. B. (2021). Understanding and tuning the electrical conductivity of activated carbon: A state-ofthe-art review. Critical Reviews in Solid State and Materials Sciences, 46(1), 1-37. https://doi.org/10.1 080/10408436.2019.1671800

Bhat, V. S., Krishnan, S. G., Jayeoye, T. J., Rujiralai, T., Sirimahachai, U., Viswanatha, R., Khalid, M., \& Hegde, G. (2021). Self-activated 'green' carbon nanoparticles for symmetric solid-state supercapacitors. Journal of Materials Science, 56(23), 13271-13290. https://doi.org/10.1007/s10853-021-06154-z

Chang, J., Gao, Z., Wang, X., Wu, D., Xu, F., Wang, X., Guo, Y., \& Jiang, K. (2015). Activated porous carbon prepared from paulownia flower for high performance supercapacitor electrodes. Electrochimica Acta, 157, 290-298. https://doi.org/10.1016/j.electacta.2014.12.169

Chen, H., Wei, H., Fu, N., Qian, W., Liu, Y., Lin, H., \& Han, S. (2018). Nitrogen-doped porous carbon using $\mathrm{ZnCl}_{2}$ as activating agent for high-performance supercapacitor electrode materials. Journal of Materials Science, 53(4), 2669-2684. https://doi.org/10.1007/s10853-017-1453-3

Chen, S., Qiu, L., \& Cheng, H. M. (2020). Carbon-based fibers for advanced electrochemical energy storage devices. Chemical Reviews, 120(5), 2811-2878. https://doi.org/10.1021/acs.chemrev.9b00466

Chen, W., Luo, M., Yang, K., \& Zhou, X. (2020). Microwave-assisted KOH activation from lignin into hierarchically porous carbon with super high specific surface area by utilizing the dual roles of inorganic salts: Microwave absorber and porogen. Microporous and Mesoporous Materials, 300, Article 110178. https://doi.org/https://doi.org/10.1016/j.micromeso.2020.110178 
Cheng, Y., Wu, L., Fang, C., Li, T., \& Chen, J. (2020). Synthesis of porous carbon materials derived from Laminaria japonica via simple carbonization and activation for supercapacitors. Journal of Materials Research and Technology, 9(3), 3261-3271. https://doi.org/10.1016/j.jmrt.2020.01.022

Chime, U. K., Nkele, A. C., Ezugwu, S., Nwanya, A. C., Shinde, N. M., Kebede, M., Ejikeme, P. M., Maaza, M., \& Ezema, F. I. (2020). Recent progress in nickel oxide-based electrodes for high-performance supercapacitors. Current Opinion in Electrochemistry, 21, 175-181. https://doi.org/https://doi. org/10.1016/j.coelec.2020.02.004

Chiu, Y. H., \& Lin, L. Y. (2019). Effect of activating agents for producing activated carbon using a facile onestep synthesis with waste coffee grounds for symmetric supercapacitors. Journal of the Taiwan Institute of Chemical Engineers, 101, 177-185. https://doi.org/10.1016/j.jtice.2019.04.050

Chmiola, J., Yushin, G., Gogotsi, Y., Portet, C., Simon, P., \& Taberna, P. L. (2006). Anomalous increase in carbon capacitance at pore sizes less than 1 nanometer. Science, 313(5794), 1760-1763. https://doi. org/10.1126/science.1132195

Chowdhury, T. S., \& Grebel, H. (2019). Supercapacitors with electrical gates. Electrochimica Acta, 307, 459464. https://doi.org/10.1016/j.electacta.2019.03.222

Devillers, N., Jemei, S., Péra, M. C., Bienaimé, D., \& Gustin, F. (2014). Review of characterization methods for supercapacitor modelling. Journal of Power Sources, 246, 596-608. https://doi.org/https://doi. org/10.1016/j.jpowsour.2013.07.116

Dresselhaus, M. S., Dresselhaus, G., Saito, R., \& Jorio, A. (2005). Raman spectroscopy of carbon nanotubes. Physics Reports, 409(2), 47-99. https://doi.org/https://doi.org/10.1016/j.physrep.2004.10.006

Elaiyappillai, E., Srinivasan, R., \& Johnbosco, Y. (2019). Applied surface science low cost activated carbon derived from Cucumis melo fruit peel for electrochemical supercapacitor application. Applied Surface Science, 486(April), 527-538.

Elmouwahidi, A., Zapata-Benabithe, Z., Carrasco-Marín, F., \& Moreno-Castilla, C. (2012). Activated carbons from $\mathrm{KOH}$-activation of argan (Argania spinosa) seed shells as supercapacitor electrodes. Bioresource Technology, 111, 185-190. https://doi.org/10.1016/j.biortech.2012.02.010

Enock, T. K., King'ondu, C. K., Pogrebnoi, A., \& Jande, Y. A. C. (2017). Status of biomass derived carbon materials for supercapacitor application. International Journal of Electrochemistry, 2017, 1-14. https:// doi.org/10.1155/2017/6453420

Farma, R., Deraman, M., Awitdrus, A., Talib, I. A., Taer, E., Basri, N. H., Manjunatha, J. G., Ishak, M. M., Dollah, B. N. M., \& Hashmi, S. A. (2013). Preparation of highly porous binderless activated carbon electrodes from fibres of oil palm empty fruit bunches for application in supercapacitors. Bioresource Technology, 132, 254-261. https://doi.org/10.1016/j.biortech.2013.01.044

Ghosh, S., Santhosh, R., Jeniffer, S., Raghavan, V., Jacob, G., Nanaji, K., Kollu, P., Jeong, S. K., \& Grace, A. N. (2019). Natural biomass derived hard carbon and activated carbons as electrochemical supercapacitor electrodes. Scientific Reports, 9, Article 16315. https://doi.org/10.1038/s41598-019-52006-x

Gu, W., \& Yushin, G. (2014). Review of nanostructured carbon materials for electrochemical capacitor applications: Advantages and limitations of activated carbon, carbide-derived carbon, zeolite-templated 
carbon, carbon aerogels, carbon nanotubes, onion-like carbon, and graphene. Wiley Interdisciplinary Reviews: Energy and Environment, 3(5), 424-473. https://doi.org/10.1002/wene.102

Gupta, G. K., Sagar, P., Pandey, S. K., Srivastava, M., Singh, A. K., Singh, J., Srivastava, A., Srivastava, S. K., \& Srivastava, A. (2021). In Situ fabrication of activated carbon from a bio-waste Desmostachya bipinnata for the improved supercapacitor performance. Nanoscale Research Letters, 16(1), 1-12. https:// doi.org/10.1186/s11671-021-03545-8

Hu, L., Zhu, Q., Wu, Q., Li, D., An, Z., \& Xu, B. (2018). Natural biomass-derived hierarchical porous carbon synthesized by an in Situ hard template coupled with $\mathrm{NaOH}$ activation for ultrahigh rate supercapacitors. ACS Sustainable Chemistry \& Engineering, 6(11), 13949-13959. https://doi.org/10.1021/ acssuschemeng. $8 \mathrm{~b} 02299$

Im, U. S., Kim, J., Lee, S. H., Lee, S. M., Lee, B. R., Peck, D. H., \& Jung, D. H. (2019). Preparation of activated carbon from needle coke via two-stage steam activation process. Materials Letters, 237, 22-25. https:// doi.org/https://doi.org/10.1016/j.matlet.2018.09.171

Ioannidou, O., \& Zabaniotou, A. Ã. (2007). Agricultural residues as precursors for activated carbon production - A review. Renewable and Sustainable Energy Reviews, 11, 1966-2005. https://doi.org/10.1016/j. rser.2006.03.013

Jiang, L., Yan, J., Hao, L., Xue, R., Sun, G., \& Yi, B. (2013). High rate performance activated carbons prepared from ginkgo shells for electrochemical supercapacitors. Carbon, 56, 146-154. https://doi.org/10.1016/j. carbon.2012.12.085

Kim, H., Cho, J., Jang, S. Y., \& Song, Y. W. (2011). Deformation-immunized optical deposition of graphene for ultrafast pulsed lasers. Applied Physics Letters, 98(2), Article 21104. https://doi.org/10.1063/1.3536502

Lei, E., Li, W., Ma, C., Xu, Z., \& Liu, S. (2018). $\mathrm{CO}_{2}$-activated porous self-templated N-doped carbon aerogel derived from banana for high-performance supercapacitors. Applied Surface Science, 457, 477-486. https:// doi.org/https://doi.org/10.1016/j.apsusc.2018.07.001

Li, Z., Xu, Z., Tan, X., Wang, H., Holt, C. M. B., Stephenson, T., Olsen, B. C., \& Mitlin, D. (2013). Mesoporous nitrogen-rich carbons derived from protein for ultra-high capacity battery anodes and supercapacitors. Energy \& Environmental Science, 6(3), 871-878. https://doi.org/10.1039/C2EE23599D

Liu, P., Yan, J., Guang, Z., Huang, Y., Li, X., \& Huang, W. (2019). Recent advancements of polyaniline-based nanocomposites for supercapacitors. Journal of Power Sources, 424, 108-130. https://doi.org/10.1016/j. jpowsour.2019.03.094

Lu, W., Cao, X., Hao, L., Zhou, Y., \& Wang, Y. (2020). Activated carbon derived from pitaya peel for supercapacitor applications with high capacitance performance. Materials Letters, 264, Article 127339. https://doi.org/10.1016/j.matlet.2020.127339

Luo, X., Chen, Y., \& Mo, Y. (2021). A review of charge storage in porous carbon-based supercapacitors. New Carbon Materials, 36(1), 49-68. https://doi.org/https://doi.org/10.1016/S1872-5805(21)60004-5

Lyu, L., Seong, K., Ko, D., Choi, J., Lee, C., Hwang, T., Cho, Y., Jin, X., Zhang, W., Pang, H., \& Piao, Y. (2019). Recent development of biomass-derived carbons and composites as electrode materials for supercapacitors. Materials Chemistry Frontiers, 3(12), 2543-2570. https://doi.org/10.1039/C9QM00348G 
Ma, M., Ying, H., Cao, F., Wang, Q., \& Ai, N. (2020). Adsorption of congo red on mesoporous activated carbon prepared by $\mathrm{CO}_{2}$ physical activation. Chinese Journal of Chemical Engineering, 28(4), 1069-1076. https:// doi.org/https://doi.org/10.1016/j.cjche.2020.01.016

Mhamane, D., Ramadan, W., Fawzy, M., Rana, A., Dubey, M., Rode, C., Lefez, B., Hannoyer, B., \& Ogale, S. (2011). From graphite oxide to highly water dispersible functionalized graphene by single step plant extract-induced deoxygenation. Green Chemistry, 13(8), 1990-1996. https://doi.org/10.1039/C1GC15393E

Misnon, I. I., Zain, N. K. M., Aziz, R. A., Vidyadharan, B., \& Jose, R. (2015). Electrochemical properties of carbon from oil palm kernel shell for high performance supercapacitors. Electrochimica Acta, 174(1), 78-86. https://doi.org/10.1016/j.electacta.2015.05.163

Morali, U., Demiral, H., \& Şensöz, S. (2018). Optimization of activated carbon production from sunflower seed extracted meal: Taguchi design of experiment approach and analysis of variance. Journal of Cleaner Production, 189, 602-611. https://doi.org/10.1016/j.jclepro.2018.04.084

Musa, M. S., Sanagi, M. M., Nur, H., \& Ibrahim, W. A. W. (2015). Understanding pore formation and structural deformation in carbon spheres during KOH activation. Sains Malaysiana, 44, 613-618. https://doi. org/10.17576/jsm-2015-4404-17

Namisnyk, A., \& Zhu, J. (2003). A survey of electrochemical super-capacitor technology. In Australian Universities Power Engineering Conference (pp. 1-6). University of Canterbury.

Nor, N. M., Lau, L. C., Lee, K. T., \& Mohamed, A. R. (2013). Synthesis of activated carbon from lignocellulosic biomass and its applications in air pollution control - A review. Journal of Environmental Chemical Engineering, 1(4), 658-666. https://doi.org/10.1016/j.jece.2013.09.017

Pang, P., Yan, F., Chen, M., Li, H., Zhang, Y., Wang, H., Wu, Z., \& Yang, W. (2016). Promising biomass-derived activated carbon and gold nanoparticle nanocomposites as a novel electrode material for electrochemical detection of rutin. RSC Advances, 6(93), 90446-90454. https://doi.org/10.1039/C6RA16804C

Peng, C., Yan, X. B., Wang, R. T., Lang, J. W., Ou, Y. J., \& Xue, Q. J. (2013). Promising activated carbons derived from waste tea-leaves and their application in high performance supercapacitors electrodes. Electrochimica Acta, 87, 401-408. https://doi.org/10.1016/j.electacta.2012.09.082

Purkait, T., Singh, G., Singh, M., Kumar, D., \& Dey, R. S. (2017). Large area few-layer graphene with scalable preparation from waste biomass for high-performance supercapacitor. Scientific Reports, 7, Article 15239. https://doi.org/10.1038/s41598-017-15463-w

Qin, L. (2019). Porous carbon derived from pine nut shell prepared by steam activation for supercapacitor electrode material. International Journal of Electrochemical Science, 14, 8907-8918. https://doi. org/10.20964/2019.09.20

Raju, K., \& Ozoemena, K. I. (2015). Hierarchical one-dimensional ammonium nickel phosphate microrods for high-performance pseudocapacitors. Scientific Reports, 5, Article 17629. https://doi.org/10.1038/srep17629

Rawal, S., Joshi, B., \& Kumar, Y. (2018). Synthesis and characterization of activated carbon from the biomass of Saccharum bengalense for electrochemical supercapacitors. Journal of Energy Storage, 20(October), 418-426. https://doi.org/10.1016/j.est.2018.10.009 
Rombaldo, C. F. S., \& Lisboa, A. C. L. (2014). Brazilian natural fiber (jute) as raw material for activated carbon production. Anais da Academia Brasileira de Ciências, 86, 2137-2144.

Saini, S., Chand, P., \& Joshi, A. (2021). Biomass derived carbon for supercapacitor applications: Review. Journal of Energy Storage, 39, Article 102646. https://doi.org/https://doi.org/10.1016/j.est.2021.102646

Samantray, R., \& Mishra, S. C. (2019). Saccharum spontaneum, a precursor of sustainable activated carbon: Synthesis, characterization and optimization of process parameters and its suitability for supercapacitor applications. Diamond and Related Materials, 101, Article 107598. https://doi.org/10.1016/j. diamond.2019.107598

Sayyed, S. G., Mahadik, M. A., Shaikh, A. V., Jang, J. S., \& Pathan, H. M. (2019). Nano-metal oxide based supercapacitor via electrochemical deposition . ES Energy \& Environment, 3, 25-44. https://doi. org/10.30919/esee8c211

Shimodaira, N., \& Masui, A. (2002). Raman spectroscopic investigations of activated carbon materials. Journal of Applied Physics, 92(2), 902-909. https://doi.org/10.1063/1.1487434

Shinde, P. A., \& Jun, S. C. (2020). Review on recent progress in the development of tungsten oxide based electrodes for electrochemical energy storage. ChemSusChem, 13(1), 11-38. https://doi.org/https://doi. org/10.1002/cssc.201902071

Simon, P., \& Gogotsi, Y. (2008). Materials for electrochemical capacitors. Nature Materials, 7(11), 845-854. https://doi.org/10.1038/nmat2297

Subramanian, V., Luo, C., Stephan, A. M., Nahm, K. S., Thomas, S., \& Wei, B. (2007). Supercapacitors from activated carbon derived from banana fibers. Journal of Physical Chemistry C, 111(20), 7527-7531. https://doi.org/10.1021/jp067009t

Sun, Q. (2019). Porous carbon material based on biomass prepared by $\mathrm{MgO}$ template method and $\mathrm{ZnCl}_{2}$ activation method as electrode for high performance supercapacitor. International Journal of Electrochemical Science, 14, 1-14. https://doi.org/10.20964/2019.01.50

Tan, Y. B., \& Lee, J. M. (2013). Graphene for supercapacitor applications. Journal of Materials Chemistry A, 1(47), 14814-14843. https://doi.org/10.1039/C3TA12193C

Teo, E. Y. L., Muniandy, L., Ng, E. P., Adam, F., Mohamed, A. R., Jose, R., \& Chong, K. F. (2016). High surface area activated carbon from rice husk as a high performance supercapacitor electrode. Electrochimica Acta, 192, 110-119. https://doi.org/10.1016/j.electacta.2016.01.140

Thulasi, K. M., Manikkoth, S. T., Paravannoor, A., Palantavida, S., Bhagiyalakshmi, M., \& Vijayan, B. K. (2019). Ceria deposited titania nanotubes for high performance supercapacitors. Journal of Physics and Chemistry of Solids, 135, Article 109111. https://doi.org/10.1016/j.jpcs.2019.109111

Tobi, A. R., Dennis, J. O., Zaid, H. M., Adekoya, A. A., Yar, A., \& Fahad, U. (2019). Comparative analysis of physiochemical properties of physically activated carbon from palm bio-waste. Journal of Materials Research and Technology, 8(5), 3688-3695. https://doi.org/10.1016/j.jmrt.2019.06.015

Tounsadi, H., Khalidi, A., Farnane, M., Abdennouri, M., \& Barka, N. (2016). Experimental design for the optimization of preparation conditions of highly efficient activated carbon from Glebionis coronaria L. 
and heavy metals removal ability. Process Safety and Environmental Protection, 102, 710-723. https:// doi.org/https://doi.org/10.1016/j.psep.2016.05.017

Tsang, C. H. A., Huang, H., Xuan, J., Wang, H., \& Leung, D. Y. C. (2020). Graphene materials in green energy applications: Recent development and future perspective. Renewable and Sustainable Energy Reviews, 120, Article 109656. https://doi.org/https://doi.org/10.1016/j.rser.2019.109656

Wei, H., Wang, H., Li, A., Li, H., Cui, D., Dong, M., Lin, J., Fan, J., Zhang, J., Hou, H., Shi, Y., Zhou, D., \& Guo, Z. (2019). Advanced porous hierarchical activated carbon derived from agricultural wastes toward high performance supercapacitors. Journal of Alloys and Compounds, 820, Article 153111. https://doi. org/10.1016/j.jallcom.2019.153111

Wu, F., Gao, J., Zhai, X., Xie, M., Sun, Y., Kang, H., Tian, Q., \& Qiu, H. (2019). Hierarchical porous carbon microrods derived from albizia flowers for high performance supercapacitors. Carbon, 147, 242-251. https://doi.org/10.1016/j.carbon.2019.02.072

Wu, M. B., Li, R. C., He, X. J., Zhang, H. B., Sui, W. B., \& Tan, M. H. (2015). Microwave-assisted preparation of peanut shell-based activated carbons and their use in electrochemical capacitors. Xinxing Tan Cailiao/ New Carbon Materials, 30(1), 86-91. https://doi.org/10.1016/S1872-5805(15)60178-0

Xiong, G., Meng, C., Reifenberger, R. G., Irazoqui, P. P., \& Fisher, T. S. (2014). A review of graphenebased electrochemical microsupercapacitors. Electroanalysis, 26(1), 30-51. https://doi.org/10.1002/ elan.201300238

Xu, J., Gao, Q., Zhang, Y., Tan, Y., Tian, W., Zhu, L., \& Jiang, L. (2014). Preparing two-dimensional microporous carbon from Pistachio nutshell with high areal capacitance as supercapacitor. Scientific Reports, 4, Article 5545. https://doi.org/10.1038/srep05545

Yakout, S. M., \& Sharaf El-Deen, G. (2016). Characterization of activated carbon prepared by phosphoric acid activation of olive stones. Arabian Journal of Chemistry, 9, S1155-S1162. https://doi.org/https:// doi.org/10.1016/j.arabjc.2011.12.002

Yao, F., Pham, D. T., \& Lee, Y. H. (2015). Carbon-based materials for lithium-ion batteries, electrochemical capacitors, and their hybrid devices. ChemSusChem, 8(14), 2284-2311. https://doi.org/https://doi. org/10.1002/cssc. 201403490

Yar, A., Dennis, J. O., Saheed, M. S. M., Mohamed, N. M., Irshad, M. I., Mumtaz, A., \& Jose, R. (2020). Physical reduction of graphene oxide for supercapacitive charge storage. Journal of Alloys and Compounds, 822, Article 153636. https://doi.org/https://doi.org/10.1016/j.jallcom.2019.153636

Yu, L. J., Rengasamy, K., Lim, K. Y., Tan, L. S., Tarawneh, M., Zulkoffli, Z. B., \& Yong, E. N. S. (2019). Comparison of activated carbon and zeolites' filtering efficiency in freshwater. Journal of Environmental Chemical Engineering, 7(4), Article 103223. https://doi.org/10.1016/j.jece.2019.103223

Zequine, C., Ranaweera, C. K., Wang, Z., Dvornic, P. R., Kahol, P. K., Singh, S., Tripathi, P., Srivastava, O. N., Singh, S., Gupta, B. K., Gupta, G., \& Gupta, R. K. (2017). High-performance flexible supercapacitors obtained via recycled jute: Bio-waste to energy storage approach. Scientific Reports, 7(1), 1-12. https:// doi.org/10.1038/s41598-017-01319-w 
Zhang, Y., Song, X., Xu, Y., Shen, H., Kong, X., \& Xu, H. (2019). Utilization of wheat bran for producing activated carbon with high specific surface area via $\mathrm{NaOH}$ activation using industrial furnace. Journal of Cleaner Production, 210, 366-375. https://doi.org/https://doi.org/10.1016/j.jclepro.2018.11.041

Zhang, Z. P., Rong, M. Z., Zhang, M. Q., \& Yuan, C. (2013). Alkoxyamine with reduced homolysis temperature and its application in repeated autonomous self-healing of stiff polymers. Polymer Chemistry, 4(17), 4648-4654. https://doi.org/10.1039/C3PY00679D

Zhu, Z., Liu, Y., Ju, Z., Luo, J., Sheng, O., Nai, J., Liu, T., Zhou, Y., Wang, Y., \& Tao, X. (2019). Synthesis of diverse green carbon nanomaterials through fully utilizing biomass carbon source assisted by KOH. ACS Applied Materials \& Interfaces, 11(27), 24205-24211. https://doi.org/10.1021/acsami.9b08420 